\title{
Energy assessment of an R134a refrigeration plant upgraded to an indirect system using R152a and R1234ze(E) as refrigerants
}

\author{
D. Sánchez ${ }^{a *}$, R. Cabello ${ }^{a}$, R. Llopis ${ }^{a}$, J. Catalán-Gil ${ }^{a}$, L. Nebot-Andrés ${ }^{a}$ \\ a Jaume I University, Dep. of Mechanical Engineering and Construction, Campus de Riu Sec s/n \\ E-12071, Castellón, Spain \\ *Corresponding author: sanchezd@uji.es Tel.: +34 964728142; Fax.: +34 964728106
}

\section{ABSTRACT}

In this work the experimental results obtained from a direct expansion refrigerating plant converted into an indirect plant, are presented and discussed in terms of energy consumption for a commercial refrigerating unit plugged to a medium temperature cabinet. Refrigerants used in the analysis are R134a for direct system, and R134a, R152a and R1234ze(E) for indirect system. The evaluation has been performed at laboratory conditions using three different heat rejection levels: $43.6,32.8$ and $23.3 \circ \mathrm{C}$ keeping constant the environmental conditions in the cabinet (25ㄷ; 55\%). From the experimental tests performed during 24 hours, it has been demonstrated that the adoption of an indirect configuration results in an increment of the total energy consumption of the refrigerating plant regardless the refrigerant adopted. The average increment registered was $21.8 \%$ for R134a, $18.7 \%$ for R152a and finally $27.2 \%$ for $\mathrm{R} 1234 z \mathrm{E}(\mathrm{E})$. The adoption of an indirect system also reduces the refrigerant mass charge of the facility up to $62 \%$ depending on the refrigerant used.

\section{KEYWORDS}

Commercial refrigeration, indirect system, R134a, R152a, R1234ze(E), energy consumption, refrigerant charge reduction

\section{HIGHLIGHTS}

- An energy quantification of the conversion from a direct expansion to an indirect system is presented and discussed.

- The experimental analyses have been performed with a commercial refrigerating plant for medium temperature.

- The conversion to indirect system is compared at three different heat rejection temperatures with three different refrigerants: R134a, R152a and R1234ze(E).

- Results show an average increment in energy consumption of $22.6 \%$.

- The refrigerant mass charge is reduced up to $62 \%$ depending on the refrigerant used.

- R152a allow the minimum average increment of $18.7 \%$ 


\begin{tabular}{|c|c|}
\hline$C_{P}$ & isobaric specific heat $\left(\mathrm{kJ} \cdot \mathrm{kg}^{-1} \cdot \mathrm{K}^{-1}\right)$ \\
\hline COP & coefficient of performance \\
\hline DX & direct expansion system \\
\hline E & electrical energy $(\mathrm{kW} \cdot \mathrm{h})$ \\
\hline $\mathrm{GWP}_{100}$ & global warming potential (at 100 years) \\
\hline $\mathrm{h}$ & specific volume $\left(\mathrm{kJ} \cdot \mathrm{kg}^{-1}\right)$ \\
\hline HFC & hydrofluorocarbons \\
\hline HFO & hydrofluoroolefins \\
\hline $\mathrm{HOC}$ & heat of combustion $\left(\mathrm{MJ} \cdot \mathrm{kg}^{-1}\right)$ \\
\hline$\dot{\mathrm{m}}$ & mass flow rate $\left(\mathrm{kg} \cdot \mathrm{s}^{-1}\right)$ \\
\hline $\mathrm{MW}$ & molecular weight $\left(\mathrm{kg} \cdot \mathrm{kmol}^{-1}\right)$ \\
\hline NBP & normal boiling point $(\stackrel{\circ}{ } \mathrm{C})$ \\
\hline$P$ & pressure (MPa) / power consumption (W) \\
\hline POE & polyolester oil \\
\hline $\mathrm{q}_{\mathrm{v}}$ & volumetric refrigerating effect $\left(\mathrm{kJ} \cdot \mathrm{m}^{-3}\right)$ \\
\hline $\mathrm{RH}$ & relative humidity $(\%)$ \\
\hline$\dot{\mathrm{q}}$ & volumetric flow rate $\left(\mathrm{m}^{3} \cdot \mathrm{h}^{-1}\right)$ \\
\hline$\dot{\mathrm{Q}}$ & cooling capacity $(\mathrm{kW})$ \\
\hline SF & secondary fluid - indirect expansion system \\
\hline $\mathrm{SH}$ & useful superheating $(\mathrm{K})$ \\
\hline $\mathrm{t}$ & time $(\mathrm{sec})$ \\
\hline $\mathrm{T}$ & temperature $(\stackrel{\circ}{ } \mathrm{C})$ \\
\hline $\mathrm{v}$ & specific volume $\left(\mathrm{m}^{3} \cdot \mathrm{kg}^{-1}\right)$ \\
\hline \multicolumn{2}{|c|}{ Greek Symbols } \\
\hline$\Delta$ & variation (increment or decrement) \\
\hline$\lambda$ & latent heat of phase change $\left(\mathrm{kJ} \cdot \mathrm{kg}^{-1}\right)$ \\
\hline$\rho$ & density $\left(\mathrm{kg} \cdot \mathrm{m}^{-3}\right)$ \\
\hline \multicolumn{2}{|c|}{ Subscripts } \\
\hline air & air \\
\hline env & environment \\
\hline$c a b$ & cabinet \\
\hline cham & climatic chamber \\
\hline comp & compressor \\
\hline Dis & discharge \\
\hline$H X$ & Heat exchanger - finned coil \\
\hline $\mathrm{imp}$ & impulsion \\
\hline in & inlet / inner \\
\hline $\mathrm{K}$ & condenser \\
\hline 0 & evaporator \\
\hline out & outlet / out \\
\hline pump & secondary fluid pump \\
\hline ref & refrigerant \\
\hline ret & return \\
\hline Sat & saturation \\
\hline sf & secondary fluid \\
\hline $\mathrm{v}$ & vapour \\
\hline w & water \\
\hline
\end{tabular}




\section{Introduction}

The field of commercial refrigeration is a widely known industry that consumes large amounts of electrical energy and fluorinated gases. In terms of energy, approximately $3-4 \%$ of the worldwide electricity production is used in supermarkets or grocery-stores [1]. Of this, a standard supermarket addresses between 30 and $60 \%$ to refrigeration process $[2,3]$ which means important running costs and a large contribution to carbon dioxide emissions (indirect effect) [1]. From an environmental point of view, more than $85 \%$ of the total fluorinated substances consumed by Europe in 2010 (40\% of the worldwide consumption) were used in supermarkets in terms of R134a (GWP 100 : 1300), R404A (GWP 100 : 3943) or R507A (GWP 100 : $3985)$ among others $[4,5]$. Considering that centralized systems are commonly adopted in supermarkets with large charges of refrigerants (20 to $3000 \mathrm{~kg}$ according to $[6,7]$ ) and important leakage rates ( 3 to $22 \%$ according to [8]), the contribution to global warming in terms of direct effect becomes worrying in this sector. According to EPA [7], approximately $26 \%$ of global HFCs emissions in 2020 will correspond to commercial refrigeration due to the lifecycle of equipment (installation, operation, end-of-life...).

Taking into account these issues, in 2016 the Kigali Amendment [9] included the HFCs on the Montreal Protocol (1998) with the objective to reduce the use and production of fluorinated gases worldwide. This amendment establishes a phase-down schedule for HFCs similar to that adopted by the European Directive 517/2014 (also known as F-Gas) in accordance with the objectives marked by the EU Research and Innovation programme Horizon 2020. Among the restrictions adopted by F-Gas in commercial refrigeration, there is a limitation in the use of refrigerants with $\mathrm{GWP}_{100}$ higher than 150 in multiplex centralized refrigeration systems with direct expansion and cooling capacity higher than $40 \mathrm{~kW}$. This prohibition will be adopted from 2020 onwards except for primary circuits of cascade systems, whose maximum GWP $_{100}$ has reduced to 1500 if no direct expansion is used for medium temperature supply.

To be in line with this position, supermarkets, and in particular European supermarkets, need to adopt changes in their facilities in the new ones. At present, one of the potential long-term solutions for multipack centralized refrigeration systems consists in using indirect expansion systems where a closed loop filled with a secondary fluid is installed between the centralized refrigeration system and the cooling services. This configuration provides several advantages against multiplex centralized refrigeration systems with direct expansion [10 - 13]:

a) It simplifies significantly the refrigerant leaks through the distribution lines because all the refrigerant charge is confined in the machinery room and the distribution lines of refrigerant are suppressed and replaced by secondary fluid lines.

b) It reduces drastically the total charge of refrigerant up to $90 \%$ [14, 15]. In any case, the reduction of refrigerant charge will depend on the modifications adopted over the refrigerating plant; use of brazed-plate heat exchangers, reduction of the liquid accumulator tank... etc.

c) It allows operating with non-A1 refrigerants (flammable or toxic fluids) or A1 refrigerants with $\mathrm{GWP}_{100}$ lower than 1500 .

d) Secondary fluids are normally non-toxic fluids and environmentally friendly. 
e) It offers a much simpler installation since secondary fluid loop does not need oxyacetylene welding to provide stronger brazing and even plastic piping can be used. In contrast, it could be up to $30 \%$ more expensive that DX-systems [11].

f) It allows manufacturers to provide their centralized refrigeration plants as a "close box" without the need for additional refrigerant connections. This reduces potential leakages.

g) Finally, indirect systems provide a relative simple reconversion of an existing centralized refrigeration plant increasing its lifetime.

In contrast, indirect layout uses a fluid pump and an additional heat exchanger resulting in higher energy consumption due to the power consumption of the pump and the extra temperature difference required in the liquid cooler, which reduces the evaporation temperature of the refrigerating plant [10]. This extra energy consumption penalizes the indirect effect but it can be minimized with a correct design of the indirect circuit (layout, length of piping, insulation...) $[10,11]$. To take into account the overall effect of the conversion from a direct to an indirect system, the sum of both carbon dioxide emissions (also known as TEWI) is usually used to report the environmental benefits. Although it depends on several assumptions, TEWI on indirect expansion systems can be reduced up to $79 \%$ with regard to a conventional direct expansion systems using R404A as refrigerant $[16,17]$.

From literature it is possible to find theoretical and experimental analysis where energy consumption, refrigerant mass reduction and TEWI of both systems are discussed. Thus, Inlow and Groll [18] compared from a theoretically point of view, the use of indirect expansion in a double stage refrigerating plant operating with economizer and using HCFC-22 as a refrigerant. The analysis was carried out with two evaporation levels of medium temperature (MT) and low temperature (LT) using different secondary fluids at each configuration. Therefore, for MT propylene-glycol solution at $50 \%, \mathrm{CO}_{2}$ and hydrofluorether (HFE) were used, while $\mathrm{HFE}, \mathrm{CO}_{2}$ and a synthetic organic fluid were selected for LT. Assuming the same condensing temperature $(40.6 \circ \mathrm{C})$, similar air temperatures at inlet of the air coil $\left(5.6{ }^{\circ} \mathrm{C}\right.$ and $\left.-20^{\circ} \mathrm{C}\right)$, and optimized diameters for the coil and interconnecting pipes, the results revealed that $\mathrm{CO}_{2}$ is the best option for both configurations against the other alternatives due to its higher density, low viscosity and higher evaporating temperature. Clodic et al. [19], compared direct and indirect alternatives taking as reference a French supermarket with a sales area bigger than $10000 \mathrm{~m}^{2}$ and a global cooling capacity of $910 \mathrm{~kW}$ ( $90 \%$ for MT and 10\% for LT). The refrigerant used in both configurations was R404A and the secondary fluids selected for MT and LT were propylene-glycol and Tyfoxit ${ }^{\circledR}$ 1.2, respectively. The results obtained from calculation revealed that the indirect layout allows reducing more than $55 \%$ of the total refrigerant charge with an increment in the global energy consumption of $33 \%$. The over consumption was associated with the lower temperature at evaporators of secondary fluids (at least 6K in MT and 7K in LT) and the energy consumption of circulation pumps which represented around $12 \%$ of the total energy consumption. You [20] compared from an experimental point of view two Sweden supermarkets with different refrigeration systems using R404A as refrigerant. The first one was a direct expansion system with a secondary condensing cycle, and the second one was a completely indirect system with evaporator and condenser connected to two secondary cycles using Temper $^{\circledast}-40$ as secondary fluid. For a sales area of $1300 \mathrm{~m}^{2}$ and a cooling capacity of 
$19.8 \mathrm{~kW}$, the results showed a refrigerant mass reduction of $88.1 \%$ and total energy savings of $16.6 \%$ using indirect arrangement including a subcooler in the refrigerant cycle. The parameter TEWI was also obtained using a conversion factor of $0.04 \mathrm{~kg} \mathrm{CO}$ eq./ $\mathrm{kWh}$ (Sweden) with a reduction of $69 \%$ in the indirect system. Faramarzi and Walker [21] presented a consultant report about the use of secondary loops in supermarket refrigeration systems. In their work, they used a theoretical and experimental comparative based on two supermarkets. The first one located in Thousand Oaks (California - USA) with a sales area of $3894 \mathrm{~m}^{2}$ and equipped with an indirect refrigeration system with two secondary loops for medium and low temperature. The second one located in Valencia (Spain) with exactly the same sales area but with a multiplex refrigeration system for two refrigerating levels, medium and low temperature. Using R507A as a refrigerant and the organic-salt Dynalene ${ }^{\circledR}$ as secondary fluid, the results showed annual savings by the secondary loop system of $14.9 \%$ and $0.3 \%$, for aircooled condensing and evaporative condensing, respectively. For the secondary arrangement, improved displays designed for use with secondary fluid, multiple-parallel pumps, evaporative heat rejection, warm-fluid defrosting and high-efficiency reciprocating compressors were used. Arias [22] simulated the operation of a supermarket with a total area of $2700 \mathrm{~m}^{2}$ working with direct and indirect refrigeration systems. The refrigerant used in both cases was R404A with two secondary fluid loops of Propylene-glycol at $35 \%$ for medium temperature, and $\mathrm{CO}_{2}$ for low temperature. The results obtained revealed an increment of 3\% in the total energy consumption when indirect system was used, but a reduction of $20.7 \%$ in terms of total emissions using a conversion factor of $0.51 \mathrm{~kg} \mathrm{CO}$ eq. $/ \mathrm{kWh}$ and a reduction in the refrigerant charge of $89 \%$. Zhang [23] published a theoretical study comparing different refrigerating systems in a reference supermarket of $2800 \mathrm{~m}^{2}$ : parallel racks with R404A in direct expansion, the same as before but with a secondary loop with propylene-glycol and a R290/R744 cascade with $\mathrm{CO}_{2}$ as secondary fluid in the medium temperature level. According with his calculations, the indirect arrangement consumed $15.4 \%$ more energy with a TEWI 58\% lower than the direct system. Cascade system only supposed an increment of $1 \%$ in terms of energy with a TEWI reduction of $66.6 \%$. These calculations assumed a conversion factor of $0.65 \mathrm{~kg} \mathrm{CO}_{2}$ eq. $/ \mathrm{kWh}$. Hinde et al. [24] presented a comparison of three low temperature refrigerating systems installed in a typical supermarket of $2600 \mathrm{~m}^{2}$ located in Atlanta (USA). The analysed systems were R404A direct expansion system with subcooled liquid, R404A - $\mathrm{CO}_{2}$ secondary coolant system with also subcooled liquid, and a R404A - $\mathrm{CO}_{2}$ cascade direct expansion system. The results derived from the study showed that the $\mathrm{CO}_{2}$ indirect system was able to reduce up to $3.3 \%$ of the total energy consumption and the cascade system could do the same up to $5.9 \%$. The reduction in terms of TEWI reached a decrease of $80 \%$ regarding to direct expansion system. Nguyen [25] compared theoretically three refrigeration systems based on direct and indirect expansion for Ice rinks. For direct system, a full $\mathrm{CO}_{2}$ refrigeration cycle was used while for indirect systems two alternatives where analysed: $\mathrm{NH}_{3} /$ brine and $\mathrm{CO}_{2} /$ brine using $24 \%$ $\mathrm{CaCl}_{2}$ as brine. The results obtained for an ice rink of $1800 \mathrm{~m}^{2}$ located in Stockholm with an average cooling capacity of $150 \mathrm{~kW}$ at $-8 \circ \mathrm{C}$ of evaporation temperature, revealed that the most efficient system was $\mathrm{CO}_{2}$ direct expansion with an average energy reduction of $38 \%$. Recently, Sánchez et al. [26] evaluated at laboratory conditions the energy impact caused by the conversion of a direct expansion $\mathrm{R} 134 \mathrm{a} / \mathrm{CO}_{2}$ cascade to an indirect system using Propyleneglycol and Temper ${ }^{\circledast}-20$ as secondary fluids for medium temperature. The results obtained at three different rejection temperatures revealed an energy consumption increment between 
7.6 to $14 \%$ when Propylene-glycol $40 \%$ was used and an increment between -0.3 to $11.1 \%$ when Temper $^{\circledR}$ was used.

As shown in the literature review, the use of indirect systems allows reducing drastically the amount of refrigerant in the refrigerating plant and consequently, direct emissions. However, the conversion of a direct expansion system to an indirect one provokes an energy impact that can be ranged from $+38 \%$ to $-16.6 \%$ according to the literature review. This important variation depends on the refrigerating system, the environmental temperature, the secondary fluid used in the secondary loop and the refrigerant used in the primary system, which directly affects the power consumption of the refrigerating plant.

With the aim to provide new experimental data about the conversion process from a direct to an indirect system, this work presents, at laboratory conditions, the behaviour of a refrigerating plant plugged to a MT cabinet when it is reconverted from direct to indirect expansion system. To achieve this, a series of 24 hour energy tests were performed at three heat rejection temperatures of $43.6,32.8$ and $23.3{ }^{\circ} \mathrm{C}$, maintaining the product inside the medium temperature cabinet at $2^{\circ} \mathrm{C}$. The refrigerants used in the analysis were R134a for the direct expansion arrangement, and R134a, R152a and R1234ze(E) for the indirect one. The secondary fluid used in all tests corresponded to Temper $^{\circledR}-20$ because it performs better than the mixture of propylene-glycol/water $(40 / 60 \%$ in mass) as was demonstrated in a previous work of authors [26].

The results obtained from this experimental work will allow comparing the impact of converting a direct expansion system to an indirect one, including the refrigerant mass reduction and the energy consumption variation. Moreover, the use of different refrigerants in the main circuit will determine how the refrigerant affects the energy consumption of the refrigerating plant.

\section{Experimental Methodology}

This section is devoted to describe the experimental plant used to carry out the energy evaluation as well as the test methodology employed during the experimental analysis.

\subsection{Experimental Setup}

\subsection{1 - Refrigeration facility}

The experimental facility used to evaluate the energy performance of direct and indirect expansion arrangements is schematized in the Figure 1. Basically, the refrigeration plant is divided in two parts. The first one, used in both configurations, is composed by a semihermetic compressor driven by a frequency drive, an oil separator, a water cooled brazed plate condenser, and a liquid receiver. The second part depends on the tested configuration. Thus, for direct arrangement, a vertical cabinet with glass doors is connected to the refrigerant circuit with a finned-tube evaporator and a thermostatic expansion valve as is described in Figure 1 (DX-system). For indirect layout, the same vertical cabinet has been used with a 
secondary loop composed by a brazed plate evaporator, a liquid pump with an integrated frequency drive and a finned-tube heat exchanger installed inside the cabinet (SF-system). The main characteristics of each element are summarized in Table 1.
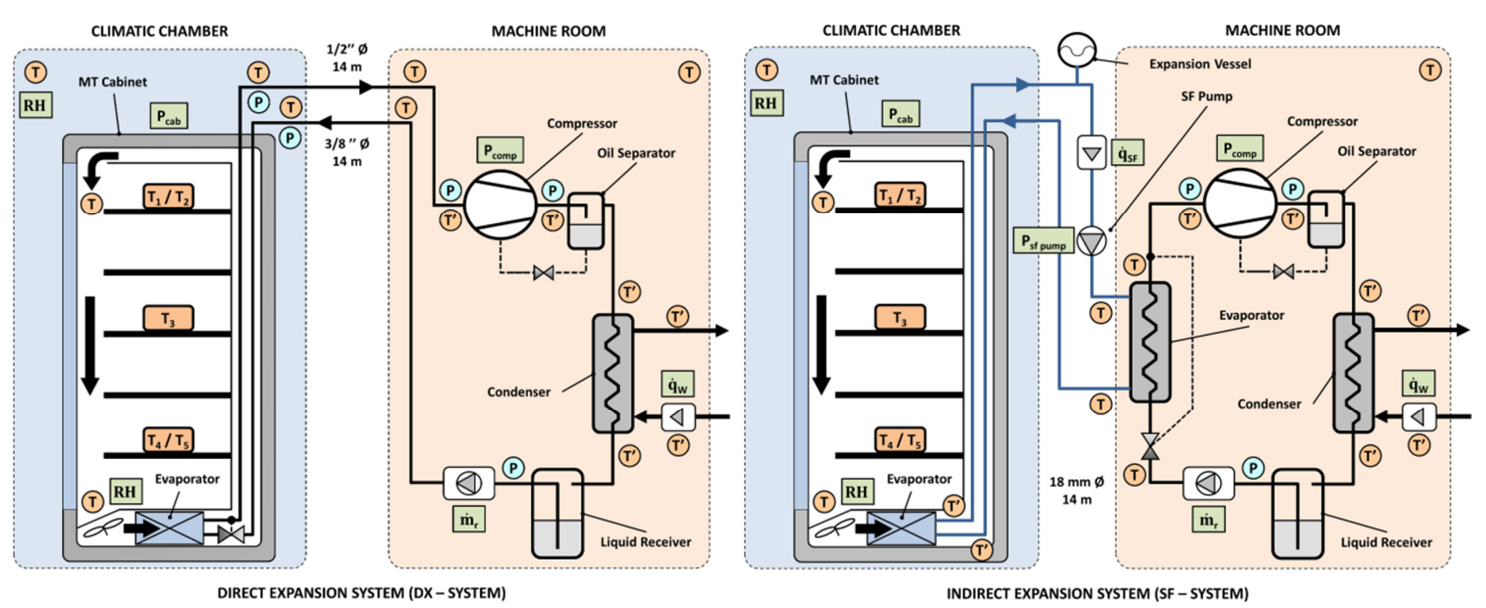

Figure 1 - Diagram for direct (left) and indirect (right) expansion systems

To minimize the heat exchange with the environment, all pipes, excepting discharge line, were insulated with a foam with an average thermal conductivity of $0.036 \mathrm{~W} \cdot \mathrm{m} \cdot \mathrm{K}^{-1}$ according to ISO 13787. Thicknesses used in each line and element are detailed in Table 1.

\begin{tabular}{|c|c|c|c|}
\hline Component & Location & BRAND / MODEL & Main characteristics \\
\hline Compressor & DX / SF system & $\begin{array}{c}\text { BITZER } \\
2 \text { HES-1Y-40S }\end{array}$ & $\begin{array}{c}\text { Semihermetic compressor } \\
\text { Displacement: } 6.5 \mathrm{~m}^{3} \cdot \mathrm{h}^{-1}(1450 \mathrm{rpm}) \\
\text { Lubricant oil: POE SL32 }\end{array}$ \\
\hline Condenser & DX / SF system & $\begin{array}{l}\text { SWEP } \\
\text { B25-THx40 }\end{array}$ & $\begin{array}{l}\text { Brazed plate heat exchanger } \\
\text { Heat transfer area: } 2.39 \mathrm{~m}^{2} \\
\text { Number of plates: } 40 \\
\text { Insulated with a thickness of } 10 \mathrm{~mm}\end{array}$ \\
\hline Liquid Accumulator & DX / SF system & - & $\begin{array}{c}\text { Volume: } 18 \text { litres (DX-system) } \\
\text { Volume: } 11 \text { litres (SF-system) } \\
\text { Insulated with a thickness of } 10 \mathrm{~mm}\end{array}$ \\
\hline Expansion Valve & DX / SF system & $\begin{array}{l}\text { CAREL } \\
\text { E2V09 }\end{array}$ & Electronic expansion valve \\
\hline Evaporator & DX system & SEREVA & $\begin{array}{c}\text { Finned-tube with } 3 \text { circuits } \varnothing 5 / 8^{\prime \prime} \\
\text { Heat transfer area: } 1.77 \mathrm{~m}^{2}\end{array}$ \\
\hline Evaporator & SF system & $\begin{array}{l}\text { SWEP } \\
\text { B8-THx20 }\end{array}$ & $\begin{array}{c}\text { Brazed plate heat exchanger } \\
\text { Heat transfer area: } 0.41 \mathrm{~m}^{2} \\
\text { Number of plates: } 20 \\
\text { Insulated with a thickness of } 10 \mathrm{~mm}\end{array}$ \\
\hline SF pump & SF system & $\begin{array}{c}\text { WILO } \\
\text { Yonos PICO-STG 15/1-13 }\end{array}$ & $\begin{array}{l}\text { Maximum volume flow: } 2 \mathrm{~m}^{3} \cdot \mathrm{h}^{-1} \\
\text { Maximum head: } 13 \mathrm{mwc} \\
\text { Power consumption: } 4-75 \mathrm{~W}\end{array}$ \\
\hline $\begin{array}{l}\text { Air-to-water heat } \\
\text { exchanger (HX) }\end{array}$ & SF system & SEREVA & $\begin{array}{c}\text { Finned-tube with } 3 \text { circuits } \varnothing 5 / 8^{\prime \prime} \\
\text { Heat transfer area: } 1.77 \mathrm{~m}^{2}\end{array}$ \\
\hline Cabinet & DX / SF system & $\begin{array}{l}\text { FROST-TROL } \\
\text { GREGAL }\end{array}$ & $\begin{array}{l}1875 \text { x } 2071 \text { x } 890 \mathrm{~mm}(\mathrm{~L} \times \mathrm{H} \times \mathrm{W}) \\
3 \text { Glass-doors and } 5 \text { sleeves }\end{array}$ \\
\hline $\begin{array}{l}\text { Line of liquid / } \\
\text { vapour }\end{array}$ & DX system & - & $\begin{array}{c}\text { Copper } \varnothing 3 / 8^{\prime \prime} / \varnothing 1 / 2^{\prime \prime} \\
\text { insulated thickness of } 6 \mathrm{~mm} / 9 \mathrm{~mm}\end{array}$ \\
\hline $\begin{array}{l}\text { Line of secondary } \\
\text { fluid }\end{array}$ & SF system & - & $\begin{array}{c}\text { Copper } \varnothing 18 \mathrm{~mm} \\
\text { insulated thickness of } 9 \mathrm{~mm}\end{array}$ \\
\hline
\end{tabular}

Table 1 - Main characteristics of refrigeration components 
From Table 1, it should be noted that the liquid accumulator used in the DX-system was replaced by other lower in the SF-system. This reduction is in accordance with the previous studies summarized in Section 1, since the evaporator used in SF-system has a volume considerably lower. The main consequence of this change is the reduction of the refrigerant mass charge as is explained in subsection 3.6.

The refrigerants used in this study were R134a, for the DX-system, and R134a, R152a and R1234ze(E), for the SF-system. R134a was selected due to its extended use in commercial refrigeration, especially in medium temperature services. R152a and R1234ze(E) were chosen as potential low $\mathrm{GWP}_{100}$ substitutes of R134a, according to the experimental analysis reported by Cabello et al. [27] and Sánchez et al. [28] at laboratory conditions.

The main characteristics of each one are summarized on Table 2.

\begin{tabular}{|c|c|c|c|c|c|c|c|c|c|}
\hline Fluid & $\begin{array}{l}\text { Chemical } \\
\text { formula }\end{array}$ & $\begin{array}{c}\mathrm{MW} \\
\left(\mathrm{kg} \cdot \mathrm{kmol}^{-1}\right)\end{array}$ & $\begin{array}{l}\text { NBP } \\
(\stackrel{\circ}{ })\end{array}$ & $\begin{array}{c}\mathbf{v}_{\text {sat, }}(\text { NBP }) \\
\left(\mathrm{m}^{3} \cdot \mathrm{kg}^{-1}\right)\end{array}$ & $\begin{array}{c}\lambda \\
(\mathrm{NBP}) \\
\left(\mathrm{kJ} \cdot \mathrm{kg}^{-1}\right)\end{array}$ & $\begin{array}{c}q_{v}(N B P) \\
\left(k J \cdot m^{-3}\right)\end{array}$ & $\begin{array}{l}\text { Safety } \\
\text { Group }\end{array}$ & $\underset{\left(\mathrm{MJ} \cdot \mathrm{kg}^{-1}\right)}{\mathrm{HOC}}$ & GWP \\
\hline HFC 134a & $\mathrm{C}_{2} \mathrm{H}_{2} \mathrm{~F}_{4}$ & 102.0 & -26.1 & 0.069 & 198.6 & 2865.4 & $\mathrm{~A} 1$ & 4.2 & 1301 \\
\hline HFC 152a & $\mathrm{C}_{2} \mathrm{H}_{4} \mathrm{~F}_{2}$ & 66.1 & -24.0 & 0.120 & 307.1 & 2567.2 & $\mathrm{~A} 2$ & 16.5 & 137 \\
\hline HFO 1234ze(E) & $\mathrm{C}_{3} \mathrm{H}_{2} \mathrm{~F}_{4}$ & 114.0 & -19.0 & 0.085 & 184.2 & 2157.6 & $\mathrm{~A} 2 \mathrm{~L}$ & 10.7 & $<1$ \\
\hline
\end{tabular}

Table 2 - Main thermodynamic, safety and environmental properties [29-31]

For the secondary fluid, Temper ${ }^{\circledast}-20$ has been used because it provides better results than propylene-glycol $40 \%$ at similar operating conditions according with [26].

\subsection{2 - Cabinet and climatic chamber}

The commercial cabinet used to carry out the analysis is a vertical type with total dimensions of $1875 \times 2071 \times 890 \mathrm{~mm}(\mathrm{~L} \times \mathrm{H} \times \mathrm{W})$. It is equipped with three glass doors, five internal sleeves and three air fans placed in the lower part of the cabinet to blow the air through the finnedtube heat exchanger (Figure 1). The cabinet incorporates a temperature controller which maintains the cabinet indoor temperature at $2 \stackrel{\circ}{ } \mathrm{C}$ adjusting the air return temperature and the defrosting period. Regarding the air temperature, the controller regulates the cooling device used in each configuration. For direct configuration, the controller acts on the thermostatic expansion valve installed inside the cabinet keeping constant the useful superheating (SH) at 7 $\mathrm{K}$. For indirect configuration, the controller acts similarly but controlling the thermostatic expansion valve installed in the brazed plate evaporator which cools down the secondary fluid pumped into the finned-tube heat exchanger installed in the cabinet. In both cases, when the cabinet indoor temperature reaches the set point, the controller closes the thermostatic valve until the return air temperature in the cabinet rises $2 \mathrm{~K}$ from the set point.

Concerning the defrosting process, it is also managed by the controller every 8 hours through electrical resistors of $2000 \mathrm{~W}$ placed at the air intake of the evaporator. The defrosting period ends when the temperature of the evaporator fin surface reaches $5 \circ \mathrm{C}$ at the air outlet. During defrosting, the expansion valves are forced to close and the secondary fluid pump is also stopped. After the defrosting process, the expansion valve starts again after the drip-off time ends (120 seconds). 
To simulate the indoor conditions of a typical supermarket, the cabinet is placed inside a climatic chamber of $31.5 \mathrm{~m}^{3}$ where temperature and relative humidity are kept at $25 \circ \mathrm{C} \pm 0.4 \circ \mathrm{C}$ and $55 \% \pm 3 \%$, respectively, by means of an evaporator, a humidifier and an electrical resistor controlled by a PID.

\subsection{3 - Heat rejection system}

The refrigeration facility is supported by an external unit devoted to maintain the desirable heat rejection conditions in tests. This unit is equipped with a water close loop pumped by a variable-speed pump and a temperature control system composed by three electrical resistors of $1500 \mathrm{~W}$ and a refrigeration unit of R134a controlled by a PID. The loop includes an accumulator tank of 150 I pressurized at 2 bars to give more thermal inertia to the system.

\subsection{4 - Data acquisition system}

As depicted in Figure 1, the refrigeration plant is fully instrumented with measuring sensors of temperature, relative humidity, pressure, power consumption and flow rate. Table 3 summarizes the main information about sensors including type, range and uncertainty.

\begin{tabular}{|c|c|c|c|c|}
\hline Quantity & Measured Variable & Measurement device & Calibration Range & Calibrated accuracy \\
\hline 20 & Temperature & T-type thermocouple & -40.0 to $125.0 \circ \mathrm{C}$ & $\pm 0.5 \stackrel{\circ}{ } \mathrm{C}$ \\
\hline 3 & Pressure (high pressure) & Pressure gauge & 0.0 to 25.0 bar & \pm 0.15 bar \\
\hline 2 & Pressure (low pressure) & Pressure gauge & 0.0 to 10.0 bar & \pm 0.06 bar \\
\hline 1 & Refrigerant mass flow rate & Coriolis mass flow meter & 0.0 to $0.1 \mathrm{~kg} \cdot \mathrm{s}^{-1}$ & $\pm 0.1 \%$ of reading \\
\hline 1 & $\begin{array}{l}\text { Secondary fluid volume rate } \\
\text { (cabinet) }\end{array}$ & Magnetic flow meter & 0.0 to $20.01 \cdot \mathrm{min}^{-1}$ & $\pm 0.25 \%$ of reading \\
\hline 1 & $\begin{array}{l}\text { Secondary fluid volume rate } \\
\text { (condenser) }\end{array}$ & Magnetic flow meter & 0.0 to $66.71 \cdot \mathrm{min}^{-1}$ & $\pm 0.25 \%$ of reading \\
\hline 1 & Power consumption (cabinet) & Digital wattmeter & 0.0 to $2500.0 \mathrm{~W}$ & $\pm 0.5 \%$ of reading \\
\hline 1 & Power consumption (sf pump) & Digital wattmeter & 0.0 to $100.0 \mathrm{~W}$ & $\pm 0.5 \%$ of reading \\
\hline 1 & $\begin{array}{l}\text { Power consumption } \\
\text { (compressor) }\end{array}$ & Digital wattmeter & 0.0 to $2000.0 \mathrm{~W}$ & $\pm 0.5 \%$ of reading \\
\hline 2 & $\begin{array}{c}\text { Temperature } \& \text { relative } \\
\text { humidity }\end{array}$ & $\begin{array}{c}\text { Combined temperature } \\
\text { and relative humidity } \\
\text { transmitter }\end{array}$ & $\begin{array}{c}5.0 \text { to } 90.0 \% \\
-20.0 \text { to } 80.0 \stackrel{\circ}{C}\end{array}$ & $\begin{array}{l} \pm 0.2 \% \mathrm{RH} \\
\pm 0.2 \circ \mathrm{C}\end{array}$ \\
\hline
\end{tabular}

Table 3 - Information about sensors installed in the experimental plant

Excluding climatic chamber and cabinet, temperature sensors are placed on the pipes and insulated from the environment with the same insulated foam mentioned above. The cabinet incorporates $5 \mathrm{M}$-test packages according to ISO 15502 placed on the five sleeves as shown in Figure 1. Each test package has dimensions of $200 \times 100 \times 50 \mathrm{~mm}$ and includes an internal Ttype thermocouple connected to the data acquisition system.

Relative humidity of the climatic chamber is measured with a combined humidity-temperature sensor placed at two meters in height separated from cabinet one meter. An additional combined humidity-temperature sensor is placed inside the cabinet at the air return duct to measure temperature and relative humidity in the cabinet. 
The power consumption of the experimental plant has been measured with three digital wattmeters installed at each power consumption element: compressor, cabinet and secondary fluid pump. The energy consumption of each element and the total energy consumption are described in subsection 2.2.3.

Regarding the flow rate of the refrigerant, it has been measured by a Coriolis mass flow meter installed in the refrigerant loop. The flow rate of the secondary fluid and the heat rejection fluid (water), have been measured by means of two magnetic flow meters installed on the corresponding loops.

All data from sensors are acquired by a cRIO-9074 data acquisition system with a register time of $5 \mathrm{~s}$ during the 24 hour test. The DAQ system includes modules for analogue signals (current and voltage) and thermocouples signals. The information gathered is registered by a personal computer with a graphic interface developed by authors [32] using RefProp [31] and ASHRAE correlations [33] to evaluate the thermophysical properties of the refrigerants and the secondary fluids, respectively.

\subsection{Test methodology}

\subsection{1 - Test conditions}

To quantify the energy consumption of the direct expansion system and its conversion to an indirect one, 24 hour tests were performed maintaining the average temperature of the product at $2{ }^{\circ} \mathrm{C}$. The energy evaluation was made using three heat rejection temperatures in the condenser $\left(43.6,32.8\right.$ and $23.3 \circ \mathrm{C}$ ) with a constant flow rate of $1 \mathrm{~m}^{3} / \mathrm{h}$ in order to cover a wide range of operating conditions.

During the tests, the rotation speed of the compressor was fixed at $1450 \mathrm{rpm}(50 \mathrm{~Hz})$, and the inner conditions of the climatic chamber were maintained at $25^{\circ} \mathrm{C} \pm 0.4{ }^{\circ} \mathrm{C}$ and $55 \% \pm 3 \%$. For indirect configuration, the flow rate of the secondary fluid was set to $2 \mathrm{l} / \mathrm{min}$ by means of the variable-speed pump detailed in Table 1.

The performed tests were conducted in the following sequence: 1st direct expansion with R134a; 2nd indirect configuration with R134a; 3rd indirect configuration with R152a; and finally 4th indirect configuration with R1234ze(E). Before starting a new test campaign with a refrigerant, the refrigerating plant was stopped and all the frost of the cabinet was removed by natural defrosting. Additionally, the expansion valve controller was updated with the corresponding P-T function in order to ensure an accurate control of the useful superheating. The lubricant oil used in all tests was the same in accordance with the oil compatibility presented by Urema et al. [34] for R152a and by Yana Motta et al. [35] for R1234ze(E).

Regarding the mass of refrigerant introduced in the facility, it was measured with an electronic weighing machine with an accuracy of $\pm 2 \mathrm{gr}$ until the liquid sight glass was completely full of liquid. 


\subsection{2 - Plant regulation}

To perform the 24 hour tests, an ON/OFF control strategy was adopted with a pressure switch installed at the compressor suction port. The pressure switch was adjusted to provide a lowcut temperature of $-24{ }^{\circ} \mathrm{C}$ and a cut-in temperature of $-7 \circ \mathrm{C}$ for direct and indirect configuration. Table 4 summarizes the cut-off and cut-in pressures adopted for each refrigerant according to the mentioned temperature levels

\begin{tabular}{cccc}
\hline Refrigerant & $\mathbf{P}_{\text {cut-off }}$ (bar) & $\mathbf{P}_{\text {cut-in }}$ (bar) & $\boldsymbol{\Delta} \mathbf{P}$ (bar) \\
\hline R134a & 1.1 & 2.3 & 1.2 \\
R152a & 1.0 & 2.0 & 1.0 \\
R1234ze(E) & 0.8 & 1.7 & 0.9 \\
\hline \multicolumn{4}{c}{ Table 4 - Absolute pressure switch values }
\end{tabular}

The operation of the pressure switch is connected with the behaviour of the thermostatic expansion valve controlled by the cabinet. Thus, when the set point temperature of the cabinet is achieved the controller turns off the valve and it shuts off the refrigerant to the evaporator. Because the circuit remains filled with refrigerant, the compressor continues running until the suction pressure is lower than the pressure cut-off value. Once the compressor is shut down, it will start again when the pressure cut-in value is achieved.

For each test condition, the set point of the cabinet was adjusted to obtain an average product temperature of $2{ }^{\circ} \mathrm{C}$ measured by the five $\mathrm{M}$-test packages. Regardless the test condition, the superheating degree at the evaporator was set to $7 \mathrm{~K}$.

\subsection{3 - Energy evaluation}

For the comparison between direct and indirect refrigeration systems, an energy evaluation was implemented considering the energy consumption of the cabinet, the compressor and the secondary fluid pump when indirect configuration is adopted. To calculate the energy consumption in $\mathrm{kW} \cdot \mathrm{h}$ from the measurements of digital wattmeters, a trapezoidal integration method has been used according to Eq. 1:

$$
E_{i}=\frac{1}{36 \cdot 10^{5}} \cdot \int_{0}^{24 h} P_{i}(t) \cdot d t \simeq \frac{1}{36 \cdot 10^{5}} \cdot \sum_{j=1}^{24 h}\left\{\left[\frac{P_{i}(j)+P_{i}(j-1)}{2}\right] \cdot[t(j)-t(j-1)]\right\}
$$

In Eq. 1, $i$ represents each energy consumer, $P$ its power consumption and $j$ each sampled data. The expression is evaluated during the 24 -hour test.

\subsection{Data validation}

To verify the coherence of data from tests, two different energy balances have been performed in the condenser and in the brazed-plate evaporator used in the SF-system. Thus, for the condenser, the heat rejected by the refrigerant $\left(\dot{Q}_{\mathrm{K}, \text { ref }}\right)$ (Eq. 2$)$ is compared with the heat gained by the water $\left(\dot{Q}_{\mathrm{K}, \mathrm{w}}\right)$ (Eq. 3). In the evaporator, the cooling capacity from the refrigerant $\left(\dot{Q}_{\text {o.ref }}\right)$ (Eq. 4$)$ is compared with the heat rejected by the secondary fluid $\left(\dot{Q}_{\text {o.sf }}\right)$ (Eq. 
5) only for a SF-system since it is not possible to determine the cooling capacity from the air side in the DX-system. Figure 2 presents graphically the data validation of both parameters averaged during the 24 hour-tests only when the compressor is running. Since the refrigerating plant is not in a steady-state condition during its operation, the experimental data presented in Figure 2 include the standard deviation as error bars in order to take into account the deviations during the transient operation.

$$
\begin{gathered}
\dot{\mathrm{Q}}_{\mathrm{K}, \mathrm{ref}}=\dot{\mathrm{m}}_{\mathrm{ref}} \cdot\left(\mathrm{h}_{\mathrm{K}, \text { in }}-\mathrm{h}_{\mathrm{K}, \text { out }}\right) \\
\dot{\mathrm{Q}}_{\mathrm{K} . \mathrm{w}}=\frac{\dot{\mathrm{q}}_{\mathrm{w}}}{3600} \cdot \rho_{\mathrm{w}, \text { in }} \cdot \mathrm{c}_{\mathrm{P}, \mathrm{w}} \cdot\left(\mathrm{T}_{\mathrm{w}, \text { out }}-\mathrm{T}_{\mathrm{w}, \text { in }}\right) \\
\dot{\mathrm{Q}}_{\mathrm{O} . \mathrm{ref}}=\dot{\mathrm{m}}_{\mathrm{ref}} \cdot\left(\mathrm{h}_{\mathrm{O}, \text { out }}-\mathrm{h}_{\mathrm{O}, \text { in }}\right) \\
\dot{\mathrm{Q}}_{\mathrm{O} . \mathrm{sf}}=\frac{\dot{\mathrm{q}}_{\mathrm{sf}}}{3600} \cdot \rho_{\mathrm{sf}, \mathrm{in}} \cdot \mathrm{c}_{\mathrm{P}, \mathrm{sf}} \cdot\left(\mathrm{T}_{\mathrm{sf} \text { out }}-\mathrm{T}_{\mathrm{sf}, \text { in }}\right)
\end{gathered}
$$

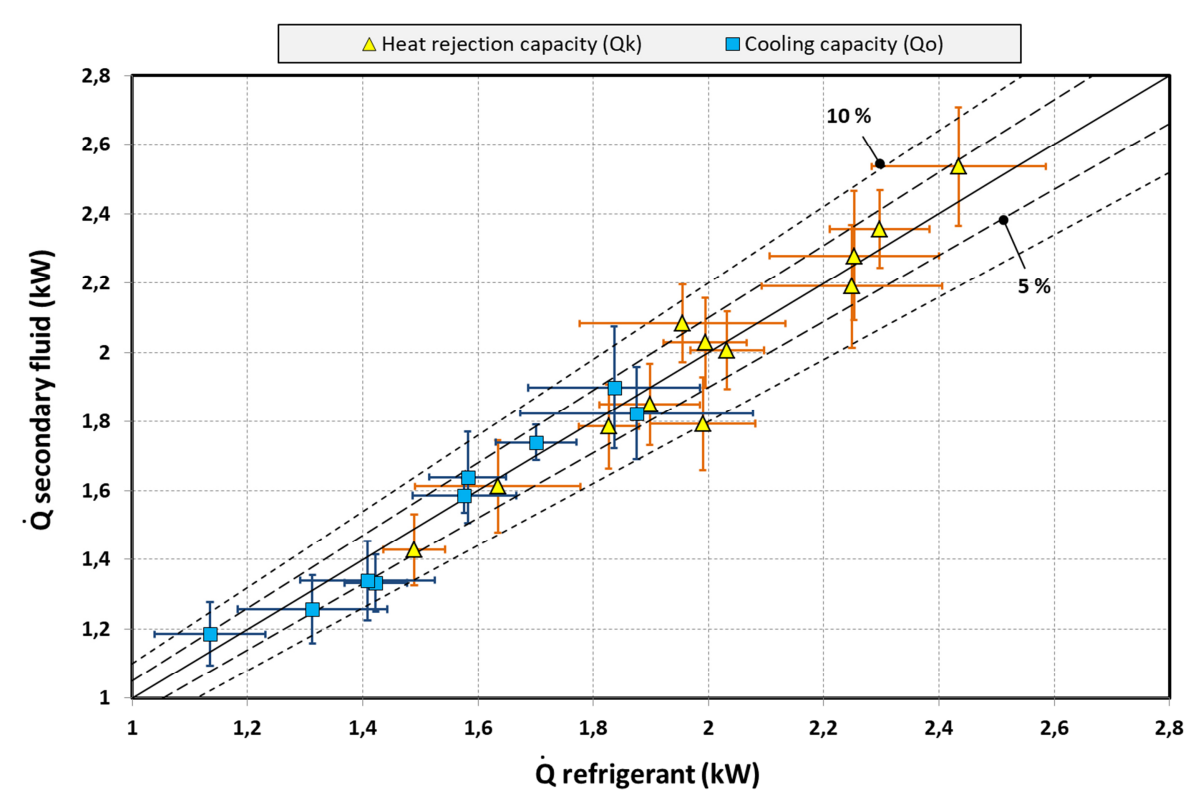

Figure 2 - Data validation for the condenser and the secondary fluid evaporator

From Figure 2, it can be appreciated that almost all experimental data obtained from the 24hour tests including its deviations have a relative error contained in a margin of $10 \%$. Accordingly, we can assume that the measurements are correct taking into account that the refrigerating plant is always working in a transient regime.

\section{Experimental Results}

In this section the results obtained from experimental tests are analysed and discussed. To make it easier, it has been divided into five parts corresponding to indicators of temperature, power consumption, operating time, energy consumption COP of the refrigerating facility and the refrigerant charge mass. Table 5 summarizes the average and the standard deviation of the parameters adopted as reference during the 24 -hour tests. 


\begin{tabular}{|c|c|c|c|c|c|c|c|c|}
\hline \multicolumn{9}{|c|}{ REFERENCE PARAMETERS } \\
\hline Configuration & \multicolumn{2}{|c|}{$T_{\text {w.in }}(\stackrel{\circ}{ })$} & \multicolumn{2}{|c|}{$\dot{q}_{\mathrm{w}}\left(\mathrm{m}^{3} / \mathrm{h}\right)$} & \multicolumn{2}{|c|}{$\mathbf{R H}_{\text {cham }}(\%)$} & \multicolumn{2}{|c|}{$\mathrm{T}_{\text {cham }}(\stackrel{\circ}{ } \mathrm{C})$} \\
\hline R134a - DX-System & 23.2 & \pm 0.2 & 1.0 & \pm 0.0 & 55.1 & \pm 6.0 & 24.8 & \pm 0.8 \\
\hline R134a - SF-System & 23.4 & \pm 0.2 & 1.0 & \pm 0.0 & 54.5 & \pm 5.4 & 24.8 & \pm 0.8 \\
\hline R152a - SF-System & 23.2 & \pm 0.2 & 1.0 & \pm 0.0 & 55.5 & \pm 6.4 & 25.7 & \pm 0.9 \\
\hline R1234ze(E) - SF-System & 23.2 & \pm 0.2 & 1.0 & \pm 0.0 & 55.0 & \pm 6.4 & 25.6 & \pm 0.9 \\
\hline R134a - DX-System & 32.7 & \pm 0.1 & 1.0 & \pm 0.0 & 53.9 & \pm 6.3 & 25.1 & \pm 0.9 \\
\hline R134a - SF-System & 32.7 & \pm 0.2 & 1.0 & \pm 0.0 & 53.9 & \pm 5.7 & 24.8 & \pm 0.8 \\
\hline R152a - SF-System & 32.9 & \pm 0.1 & 1.0 & \pm 0.0 & 52.7 & \pm 6.4 & 25.7 & \pm 0.9 \\
\hline R1234ze(E) - SF-System & 32.7 & \pm 0.2 & 1.0 & \pm 0.0 & 54.6 & \pm 6.5 & 25.5 & \pm 0.9 \\
\hline R134a - DX-System & 43.6 & \pm 0.2 & 1.0 & \pm 0.0 & 54.6 & \pm 6.0 & 24.8 & \pm 0.8 \\
\hline R134a - SF-System & 43.6 & \pm 0.1 & 1.0 & \pm 0.0 & 54.4 & \pm 5.4 & 24.8 & \pm 0.7 \\
\hline R152a - SF-System & 43.7 & \pm 0.2 & 1.0 & \pm 0.0 & 54.3 & \pm 6.1 & 25.3 & \pm 0.8 \\
\hline R1234ze(E) - SF-System & 43.5 & \pm 0.2 & 1.0 & \pm 0.0 & 54.9 & \pm 6.4 & 25.5 & \pm 0.9 \\
\hline
\end{tabular}

Table 5 - Reference parameters

In Table 5, $T_{\text {w.in }}$ represents the heat rejection temperature, $\dot{q}_{w}$ the volumetric flow rate of the secondary fluid, $R H_{\text {cham }}$ the relative humidity in the climatic chamber, and finally, $T_{\text {cham }}$ the temperature in the climatic chamber.

\subsection{Temperature indicators}

To compare the behaviour between the DX-system and the SF-system, three temperatures from the vapour compression cycle have been considered: condensing level, evaporating temperature and discharge temperature. All of them were obtained when the compressor is running during the 24 hour-tests. Condensing temperature was obtained from the average pressure at the condenser (measured with the pressure gauges) assuming liquid saturated conditions. Concerning evaporating temperature, it was obtained similarly with the pressure at the compressor suction port, assuming vapour saturated conditions. Finally, discharge temperature was directly measured with a T-type thermocouple installed in the discharge line.

Figures 3 to 5 compare the temperature indicators at each configuration and Table 6 summarizes their values. It must be highlighted that Table 6 includes the standard deviation of the measured variables which value is depicted in the Figures 3 to 5 as bar errors.

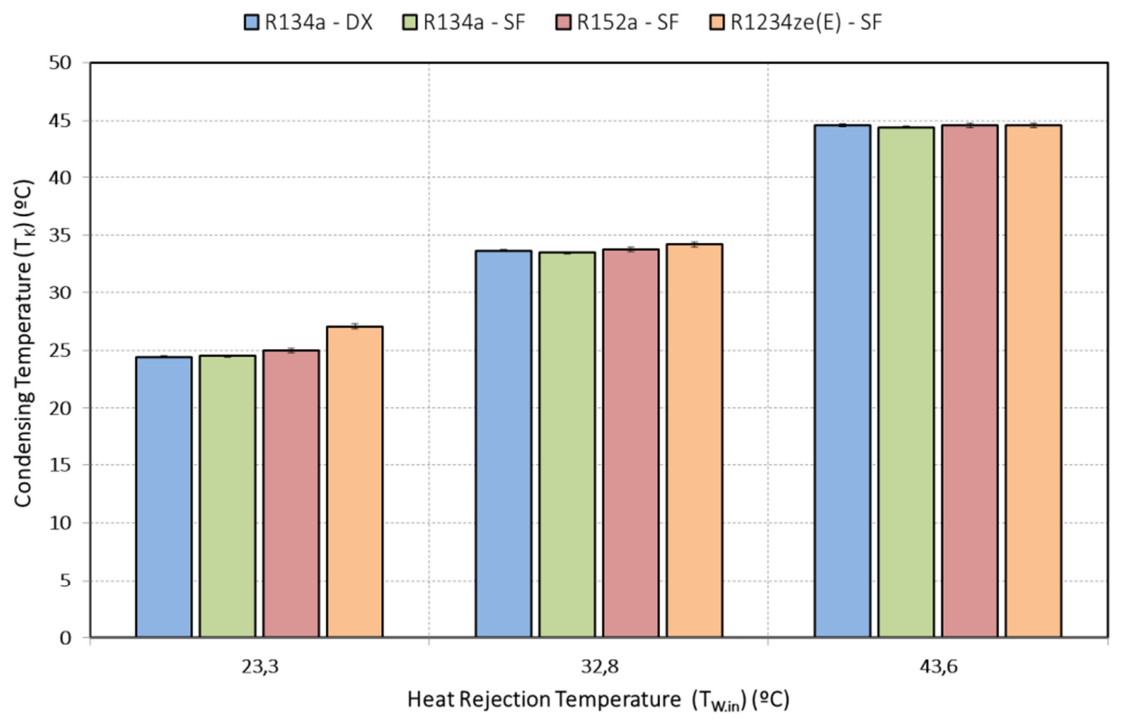

Figure 3 - Average condensing temperatures during the $24 \mathrm{~h}$ tests - Compressor ON 


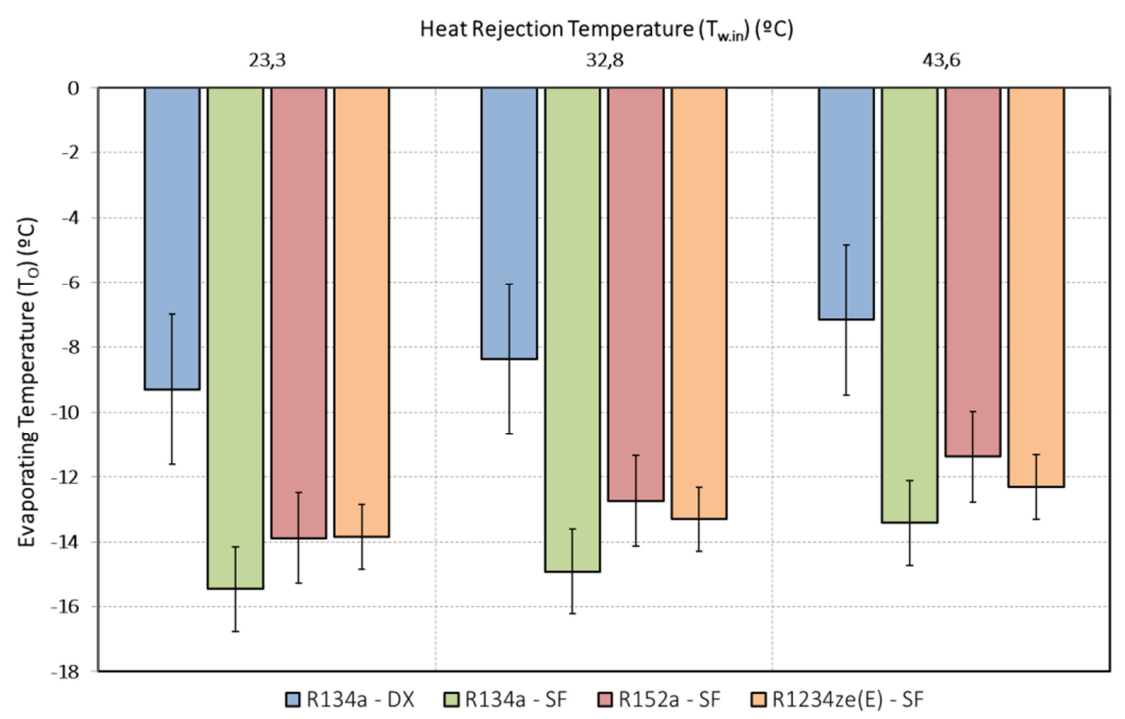

Figure 4 - Average evaporating temperatures during the $24 \mathrm{~h}$ tests - Compressor ON

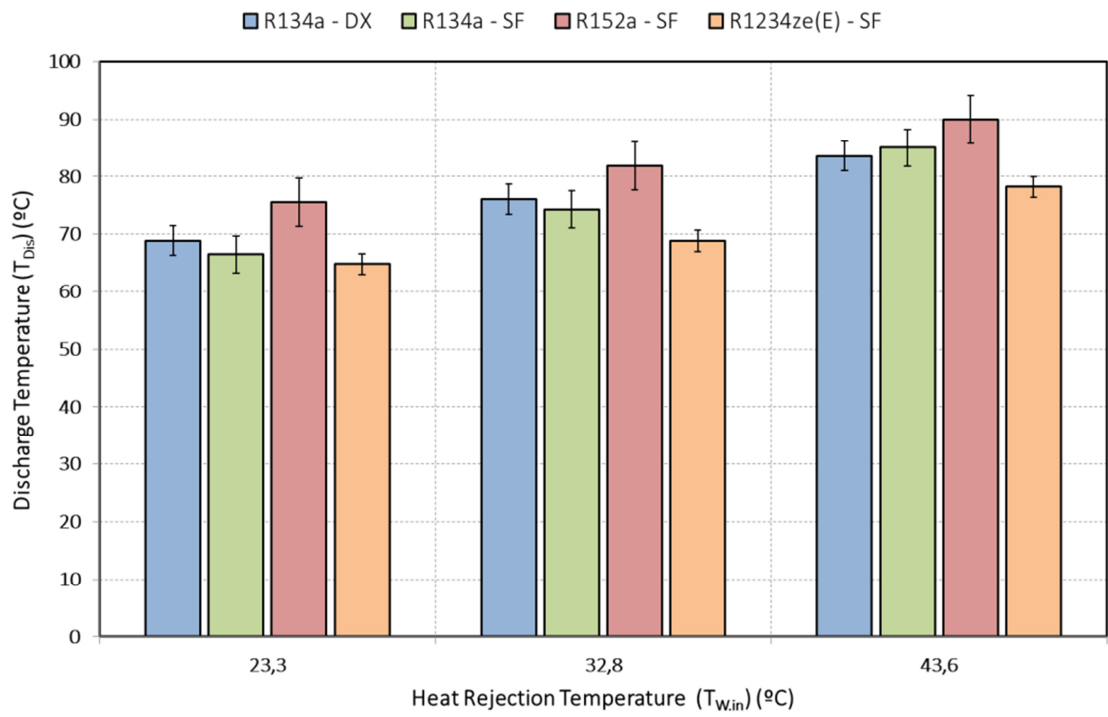

Figure 5 - Average discharge temperature during the $24 \mathrm{~h}$ tests - Compressor ON

\begin{tabular}{|c|c|c|c|c|c|c|c|c|c|}
\hline \multicolumn{10}{|c|}{ REFRIGERATING PLANT TEMPERATURES } \\
\hline Configuration & $T_{\text {w.in }}\left({ }^{\circ} \mathrm{C}\right)$ & \multicolumn{2}{|c|}{$\mathrm{T}_{\mathrm{K}}\left({ }^{\circ} \mathrm{C}\right)$} & \multicolumn{2}{|c|}{$\mathrm{T}_{0}$ (ㅇ) } & \multicolumn{2}{|c|}{$\mathrm{T}_{\mathrm{Dis}}(\mathrm{O} \mathrm{C})$} & \multicolumn{2}{|c|}{$T_{\text {env }}(O C)$} \\
\hline R134a-DX-System & & 24.4 & \pm 0.1 & -8.3 & \pm 0.8 & 67.0 & \pm 3.1 & 19.4 & \pm 0.5 \\
\hline R134a-SF-System & $232+02$ & 24.5 & \pm 0.1 & -15.4 & \pm 1.4 & 66.5 & \pm 3.6 & 20.8 & \pm 1.7 \\
\hline R152a - SF-System & $23.3 \pm 0.2$ & 25.0 & \pm 0.4 & -13.9 & \pm 1.5 & 75.4 & \pm 4.3 & 23.6 & \pm 2.2 \\
\hline R1234ze(E) - SF-System & & 27.1 & \pm 0.1 & -13.8 & \pm 1.1 & 64.8 & \pm 1.7 & 21.3 & \pm 0.7 \\
\hline R134a - DX-System & & 33.7 & \pm 0.1 & -7.7 & \pm 0.8 & 77.0 & \pm 1.5 & 19.3 & \pm 1.3 \\
\hline R134a-SF-System & & 33.5 & \pm 0.1 & -14.9 & \pm 1.4 & 74.1 & \pm 3.3 & 17.6 & \pm 1.5 \\
\hline R152a - SF-System & $32.8 \pm 0.2$ & 33.8 & \pm 0.1 & -12.8 & \pm 1.5 & 81.7 & \pm 4.6 & 18.6 & \pm 1.7 \\
\hline R1234ze(E) - SF-System & & 34.2 & \pm 0.3 & -13.2 & \pm 1.0 & 68.9 & \pm 2.1 & 18.8 & \pm 1.2 \\
\hline R134a-DX-System & & 44.6 & \pm 0.1 & -7.2 & \pm 1.9 & 83.6 & \pm 2.9 & 19.1 & \pm 1.1 \\
\hline R134a - SF-System & $436+02$ & 44.4 & \pm 0.1 & -13.4 & \pm 1.2 & 85.1 & \pm 3.1 & 19.7 & \pm 1.2 \\
\hline R152a - SF-System & $43.0 \pm 0.2$ & 44.5 & \pm 0.1 & -11.6 & \pm 1.6 & 90.3 & \pm 4.6 & 21.7 & \pm 1.8 \\
\hline R1234ze(E) - SF-System & & 44.6 & \pm 0.2 & -11.8 & \pm 1.0 & 78.1 & \pm 1.9 & 20.4 & \pm 1.9 \\
\hline
\end{tabular}

Table 6 - Temperature indicators averaged during the $24 \mathrm{~h}$ tests - Compressor ON 
Taking into account Figure 3, no significant differences are found in condensing temperature among the four alternatives. Only R1234ze $(\mathrm{E})$ reaches higher differences at $23.27^{\circ} \mathrm{C}(+2.86 \mathrm{~K})$ and $32.76 \circ \mathrm{C}(+0.48 \mathrm{~K})$ compared to the other refrigerants. This difference may be caused by the lower heat transfer coefficients of R1234ze(E) as it is explained by Zhang et al. [36]. In fact, if the temperature difference between condensing and heat rejection temperatures is calculated, R1234ze(E) presents significant differences at low heat rejection temperatures which means a reduction in the overall heat transfer coefficient.

Regarding evaporating temperature, changing from direct to indirect layout entails a notable reduction in the evaporating level that affects the behaviour of the refrigerating plant. As it is shown in Figure 4, the reductions in evaporating temperature are ranged between $-4.62 \mathrm{~K}$ and $-7.20 \mathrm{~K}$ which is in concordance with the literature review.

Discharge temperature presented in Figure 5 shows a logical increase as the heat rejection temperature rises despite the variation in the environmental temperature (Table 6). The results from experimental tests match with those obtained by Sánchez et al. [28] in a onestage vapour compression plant, where R152a was the higher discharge temperature followed by R134a and R1234ze(E).

In terms of cabinet, the conversion from direct to indirect expansion entails an increment up to $5.96 \mathrm{~K}$ in the heat exchanger temperature of the cabinet $\left(T_{H X}\right)$. This difference means that the heat exchanger runs better with a secondary fluid than with a DX-system, since it needs less temperature to achieve the same effect ( $\left.T_{\text {air, imp }}\right)$ as can be seen in Table 7 . Notwithstanding, this improvement is countered by the large temperature difference between the air return in the cabinet ( $T_{\text {air, ret }}$ ) and the evaporating temperature of the system ( $T_{0}$ ) (Eq. 6). Lower values for this parameter entail better cooling of the cabinet and, consequently, lower energy consumption of the system as will be explained in subsection 3.4.

$$
\Delta \mathrm{T}_{\text {cab }}=\mathrm{T}_{\text {air,ret }}-\mathrm{T}_{\mathrm{O}}
$$

\begin{tabular}{|c|c|c|c|c|c|c|c|}
\hline \multicolumn{8}{|c|}{ CABINET TEMPERATURES } \\
\hline Configuration & $T_{W \cdot i n}(\stackrel{\circ}{ })$ & \multicolumn{2}{|c|}{$\mathrm{T}_{\mathrm{HX}}(\stackrel{\circ}{ } \mathrm{C})$} & \multicolumn{2}{|c|}{$\mathrm{T}_{\mathrm{air}, \mathrm{imp}}(\stackrel{\mathrm{o}}{ } \mathrm{C})$} & \multicolumn{2}{|c|}{$\Delta \mathrm{T}_{\mathrm{cab}}(\mathrm{K})$} \\
\hline R134a - DX-System & \multirow{4}{*}{$23.3 \pm 0.2$} & -8.34 & \pm 0.84 & 0.50 & \pm 1.29 & 10.58 & \pm 1.09 \\
\hline R134a - SF-System & & -3.62 & \pm 1.74 & 0.94 & \pm 1.15 & 17.42 & \pm 1.10 \\
\hline R152a - SF-System & & -3.21 & \pm 1.43 & 0.98 & \pm 1.01 & 16.51 & \pm 0.97 \\
\hline R1234ze(E) - SF-System & & -2.38 & \pm 1.22 & 0.85 & \pm 0.97 & 16.32 & \pm 0.78 \\
\hline R134a - DX-System & \multirow{4}{*}{$32.8 \pm 0.2$} & -7.72 & \pm 0.83 & 0.62 & \pm 1.15 & 9.63 & \pm 0.69 \\
\hline R134a - SF-System & & -3.50 & \pm 1.31 & 0.84 & \pm 1.02 & 16.83 & \pm 0.94 \\
\hline R152a - SF-System & & -3.66 & \pm 1.31 & 0.70 & \pm 1.03 & 14.57 & \pm 0.92 \\
\hline R1234ze(E) - SF-System & & -2.16 & \pm 1.21 & 0.94 & \pm 1.04 & 16.05 & \pm 0.56 \\
\hline R134a - DX-System & \multirow{4}{*}{$43.6 \pm 0.2$} & -7.16 & \pm 1.94 & 0.70 & \pm 0.94 & 9.06 & \pm 1.63 \\
\hline R134a - SF-System & & -2.94 & \pm 1.20 & 0.76 & \pm 1.05 & 15.23 & \pm 0.82 \\
\hline R152a - SF-System & & -2.95 & \pm 1.27 & 0.91 & \pm 0.96 & 13.31 & \pm 1.15 \\
\hline R1234ze(E) - SF-System & & -2.33 & \pm 0.92 & 0.73 & \pm 0.83 & 14.89 & \pm 0.47 \\
\hline
\end{tabular}

Table 7 - Temperature indicators at cabinet averaged during the $24 \mathrm{~h}$ tests - Compressor ON

\subsection{Power indicators}

The power consumption of the refrigerating plant corresponds to the sum of each element: compressor, cabinet and secondary fluid pump. Table 8 gathers the average power 
consumption of each element during 24h-tests only when they are in operation. For compressor and pump, the power consumption of frequency drives has been included. In the case of the cabinet, the averaged power consumption during 24 hour includes the defrosting electrical resistors. It should be noted that the incorporation of this electrical power consumption entails important variation on the average value as is summarized in Table 8.

\begin{tabular}{|c|c|c|c|c|c|c|c|}
\hline \multicolumn{8}{|c|}{ POWER CONSUMPTION } \\
\hline Configuration & $\mathrm{T}_{\text {w.in }}\left({ }^{\circ} \mathrm{C}\right)$ & \multicolumn{2}{|c|}{$P_{\text {comp }}(W)$} & \multicolumn{2}{|c|}{$P_{\text {cab }}(\mathrm{W})$} & \multicolumn{2}{|c|}{$P_{\text {sf,pump }}(W)$} \\
\hline R134a-DX-System & \multirow{4}{*}{$23.3 \pm 0.2$} & 688.8 & \pm 95.2 & 112.9 & \pm 209.7 & - & - \\
\hline R134a-SF-System & & 690.2 & \pm 66.8 & 107.2 & \pm 205.7 & 7.6 & \pm 0.2 \\
\hline R152a - SF-System & & 640.3 & \pm 101.7 & 95.0 & \pm 158.9 & 6.9 & \pm 0.2 \\
\hline R1234ze(E) - SF-System & & 584.4 & \pm 66.8 & 101.9 & \pm 191.1 & 7.8 & \pm 0.2 \\
\hline R134a-DX-System & \multirow{4}{*}{$32.8 \pm 0.2$} & 755.5 & \pm 111.7 & 107.1 & \pm 180.3 & - & - \\
\hline R134a-SF-System & & 746.4 & \pm 99.1 & 108.7 & \pm 217.6 & 7.6 & \pm 0.2 \\
\hline R152a-SF-System & & 713.7 & \pm 98.8 & 95.5 & \pm 158.2 & 8.5 & \pm 0.2 \\
\hline R1234ze(E) - SF-System & & 607.8 & \pm 96.9 & 104.8 & \pm 208.0 & 8.0 & \pm 0.2 \\
\hline R134a - DX-System & \multirow{4}{*}{$43.6 \pm 0.2$} & 825.9 & \pm 129.3 & 113.3 & \pm 211.7 & - & - \\
\hline R134a - SF-System & & 804.0 & \pm 123.2 & 107.7 & \pm 210.8 & 7.4 & \pm 0.2 \\
\hline R152a-SF-System & & 786.2 & \pm 110.6 & 98.4 & \pm 169.0 & 8.4 & \pm 0.2 \\
\hline R1234ze(E) - SF-System & & 651.9 & \pm 93.0 & 101.1 & \pm 188.2 & 7.8 & \pm 0.3 \\
\hline
\end{tabular}

Table 8 - Power indicators averaged during the $24 \mathrm{~h}$ tests

From Table 8 it can be highlighted that the power consumption of the cabinet $\left(P_{c a b}\right)$ and the secondary fluid pump $\left(P_{\text {sf pump }}\right)$ are hardly affected by the configuration adopted. This is because the working conditions of the cabinet were quite similar in all the performed tests as well as the volumetric flow rate of the secondary fluid. Regarding the power of the compressor $\left(P_{\text {comp }}\right)$, no significant differences were found when R134a was used in both configurations in contrast with R152a and R1234ze(E). In these cases, R152a shows a reduction between 4.81 and $7.05 \%$ whereas R1234ze(E) reaches a value between 15.17 and $21.07 \%$. Graphically, Figure 6 shows the compressor power consumption including its variability during the operation of the refrigerating plant as error bars.

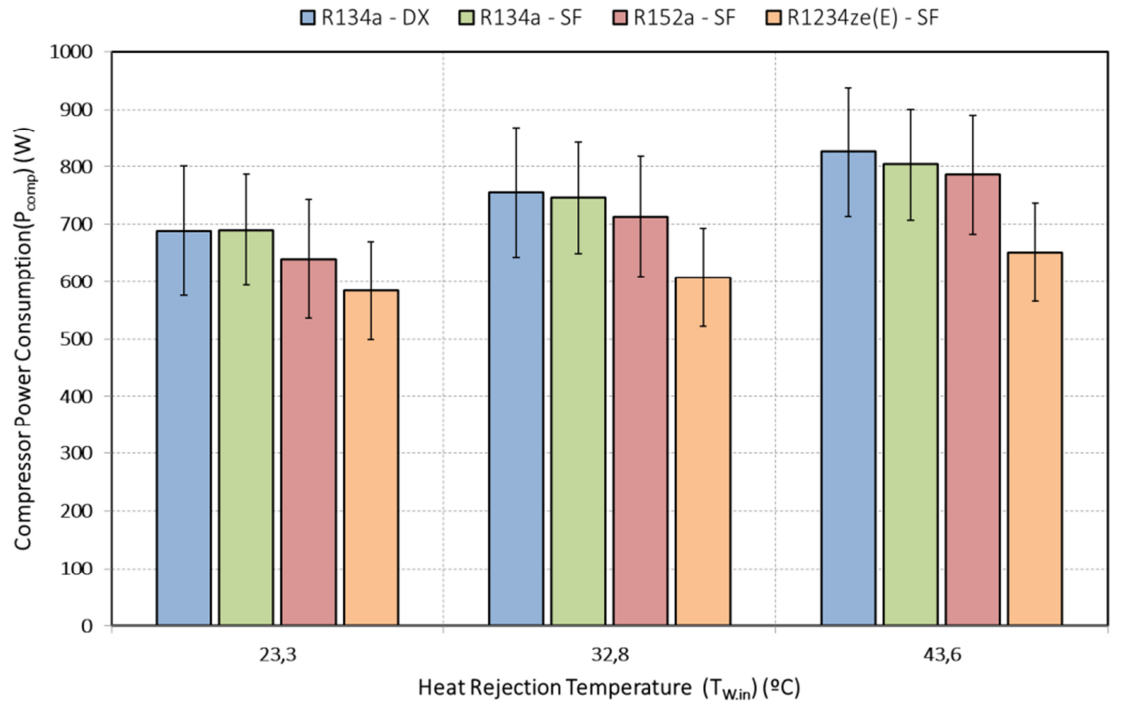

Figure 6 - Average compressor power consumption during the $24 \mathrm{~h}$ tests 


\subsection{Cooling capacity}

To determine the cooling capacity of the refrigerating plant $\left(\dot{Q}_{\text {o.ref }}\right)$, Eq. 4 is used when the compressor is running. Taking into account this premise, Figure 7 shows the average values of cooling capacity during the 24-hour tests including the standard deviation of COP as error bars.

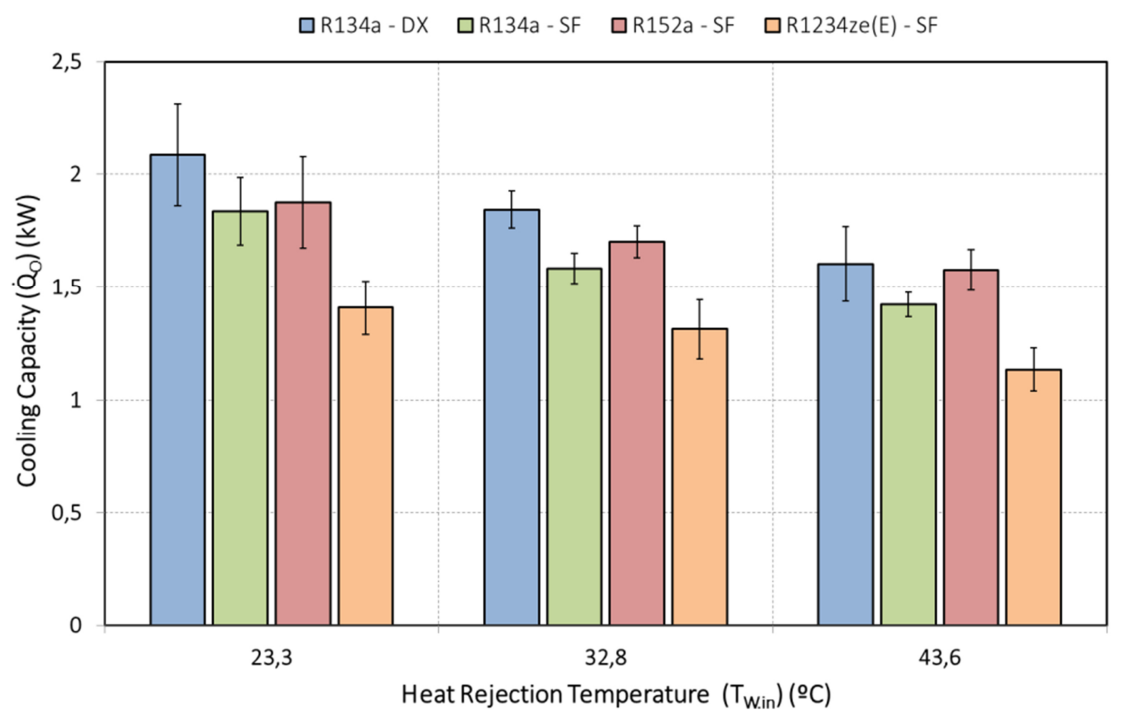

Figure 7 - Average cooling capacity during the $24 \mathrm{~h}$ tests - Compressor ON

From Figure 7, there is an evident reduction in cooling capacity when the indirect expansion arrangement is used regardless the refrigerant of the main cycle. Thus, for the heat rejection temperatures analysed, the reduction is ranged between $11.17 \%$ and $14.18 \%$ for R134a; $1.57 \%$ and $10.10 \%$ for R152a; and finally, $28.80 \%$ and $32.51 \%$ for R1234ze(E).

Comparing both configurations using R134a as refrigerant, the differences detected are mainly caused by the lower evaporating temperature reached at the indirect arrangement (Figure 4). However, if different refrigerants are compared, it should be also considered the specific volume of the refrigerant at the suction conditions. This is particularly important for the HFO R1234ze(E) whose high specific volume provokes an important reduction in terms cooling capacity regardless the operating conditions of the plant. In this case, an increment in the compressor capacity may reduce this difference.

On the other hand, the use of R152a as a refrigerant reports a cooling capacity higher than the R134a or R1234ze(E) suggesting a good low-GWP alternative to R134a in SF-systems since it is classified as A2 by ASHRAE.

\subsection{Operating time}

The operating time of the refrigeration plant is defined by the period of time in which the compressor is working. Since the electrical energy consumption of the plant is defined by the product of power electricity and operating time, it is very important to analyse how direct and indirect arrangements affect this variable. Figure 8 shows the percentage of time the compressor is working during the 24-hour test. 


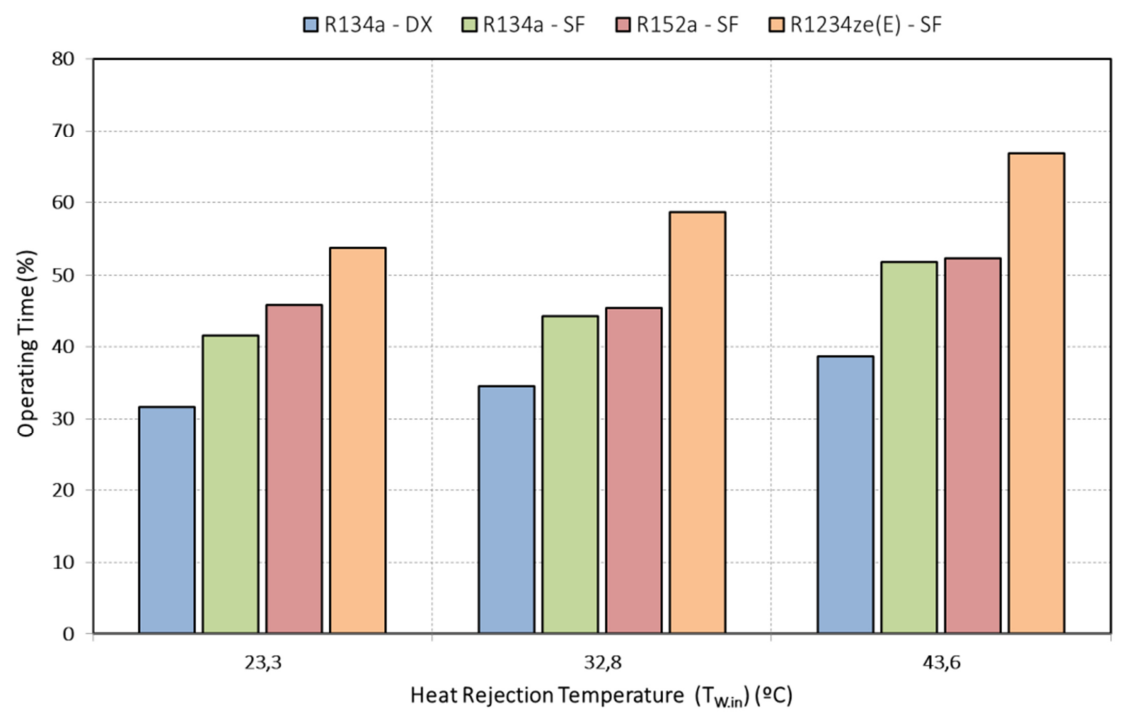

Figure 8 - Average operating time of the compressor in \% during $24 \mathrm{~h}$ test

From experimental data, it is show an evident increment in the compressor operating time when indirect layout is implemented regardless the refrigerant used. This issue is caused by the lower cooling capacity of indirect systems (Figure 7) and by the reduction of volume in the low pressure side when indirect expansion layout is installed.

As it was described in subsection 2.1.2, the conversion affects the evaporator and the pipe lines that connect it with the refrigerating plant (liquid and vapour).The use of a brazed plate heat exchanger for the secondary fluid reduces the amount of refrigerant in the low pressure side and, consequently, diminishes the time that needs the compressor to reduce the pressure level to the low pressure cut-off. In the same way, during the run-down time the low amount of refrigerant available in the brazed plate evaporator is rapidly heated by the secondary fluid, leading to a quickly achievement of the cut-in pressure. The effect described above increases the compressor operating time in average $46.4 \%$ regarding the direct expansion configuration. As it will be seen in the next subsection, the main consequence of this increment is the rising of the facility energy consumption.

In terms of refrigerants, the use of R152a results in a slight increase of operating time with regard to R134a SF-system (average 4.6\%), while R1234ze(E) provokes an average rise of $30.4 \%$ regarding R134a SF-system.

Another issue to highlight is the running time of the compressor after defrosting. This time shows how fast the facility cools down the cabinet to the set point temperature after a defrosting process. From Figure 9 it is clear that secondary fluid duplicates the operating time of the compressor due to the inertia of the secondary fluid and the lower cooling capacity, so it could be useful to increase the rotation speed of the compressor to reduce the operating time during this period. On the other hand, the cooling process depends on the refrigerant used. Thus, for R1234ze(E) the time is on average three times longer than R134a in direct expansion, which means that the compressor sweet volume for R1234ze(E) is insufficient. 


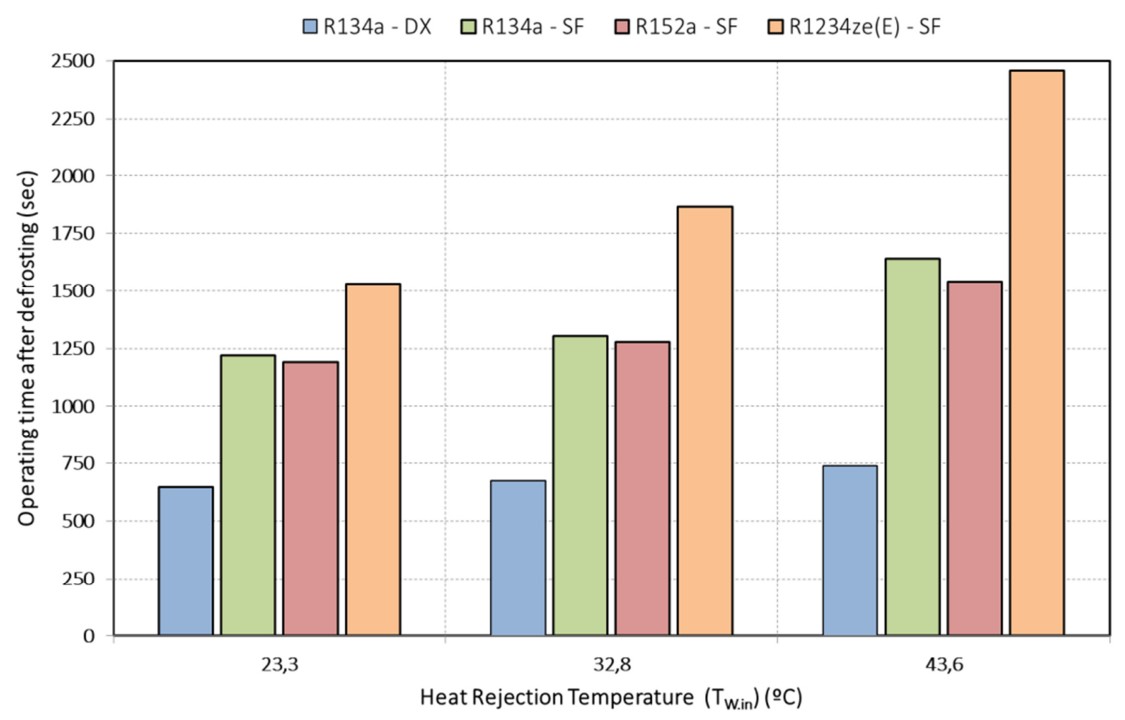

Figure 9-Operating time of the compressor after defrosting process

\subsection{Energy consumption}

As pointed out above, the energy evaluation of each element by means of Eq. 1 allows comparing direct and indirect configurations from an energy point of view. For each element, the energy consumption during the 24-hour tests is detailed in Table 9 including the relative error of the calculated energy consumption. This error has been determined indirectly by using the partial derivative analysis. Due to its low value, it has not been presented in Figure 10.

It should be noted that the energy consumption of the compressor and pump, includes the energy from the frequency drives. Regarding the cabinet, the energy demand also includes the defrosting and the control system.

\begin{tabular}{|c|c|c|c|c|c|}
\hline \multicolumn{6}{|c|}{ ENERGY CONSUMPTION DURING 24 HOURS } \\
\hline Configuration & $T_{\text {w.in }}\left({ }^{\circ} \mathrm{C}\right)$ & $E_{\text {comp }}(k W \cdot h)$ & $E_{c a b}(k W \cdot h)$ & $E_{s f, p u m p}(k W \cdot h)$ & $E_{\text {total }}(\mathrm{kW} \cdot \mathrm{h})$ \\
\hline R134a-DX-System & \multirow{4}{*}{$23.3 \pm 0.2$} & $5.22 \pm 0.03$ & $2.71 \pm 0.01$ & - & $7.93 \pm 0.04$ \\
\hline R134a-SF-System & & $6.87 \pm 0.03$ & $2.57 \pm 0.01$ & $0.18 \pm 0.00$ & $9.63 \pm 0.05$ \\
\hline R152a-SF-System & & $7.07 \pm 0.04$ & $2.28 \pm 0.01$ & $0.17 \pm 0.00$ & $9.51 \pm 0.05$ \\
\hline R1234ze(E) - SF-System & & $7.53 \pm 0.04$ & $2.44 \pm 0.01$ & $0.19 \pm 0.00$ & $10.16 \pm 0.05$ \\
\hline R134a - DX-System & \multirow{4}{*}{$32.8 \pm 0.2$} & $6.25 \pm 0.03$ & $2.57 \pm 0.01$ & - & $8.82 \pm 0.04$ \\
\hline R134a - SF-System & & $7.90 \pm 0.04$ & $2.61 \pm 0.01$ & $0.18 \pm 0.00$ & $10.69 \pm 0.05$ \\
\hline R152a - SF-System & & $7.75 \pm 0.04$ & $2.29 \pm 0.01$ & $0.20 \pm 0.00$ & $10.24 \pm 0.05$ \\
\hline R1234ze(E) - SF-System & & $8.55 \pm 0.04$ & $2.52 \pm 0.01$ & $0.19 \pm 0.00$ & $11.25 \pm 0.06$ \\
\hline R134a - DX-System & \multirow{4}{*}{$43.6 \pm 0.2$} & $7.65 \pm 0.04$ & $2.72 \pm 0.01$ & - & $10.37 \pm 0.05$ \\
\hline R134a - SF-System & & $9.98 \pm 0.05$ & $2.58 \pm 0.01$ & $0.18 \pm 0.00$ & $12.74 \pm 0.06$ \\
\hline R152a - SF-System & & $9.86 \pm 0.05$ & $2.36 \pm 0.01$ & $0.20 \pm 0.00$ & $12.43 \pm 0.06$ \\
\hline R1234ze(E) - SF-System & & $10.44 \pm 0.052$ & $2.43 \pm 0.01$ & $0.19 \pm 0.00$ & $13.05 \pm 0.07$ \\
\hline
\end{tabular}

Table 9 - Energy consumption accumulated for each element during the $24 \mathrm{~h}$-test 


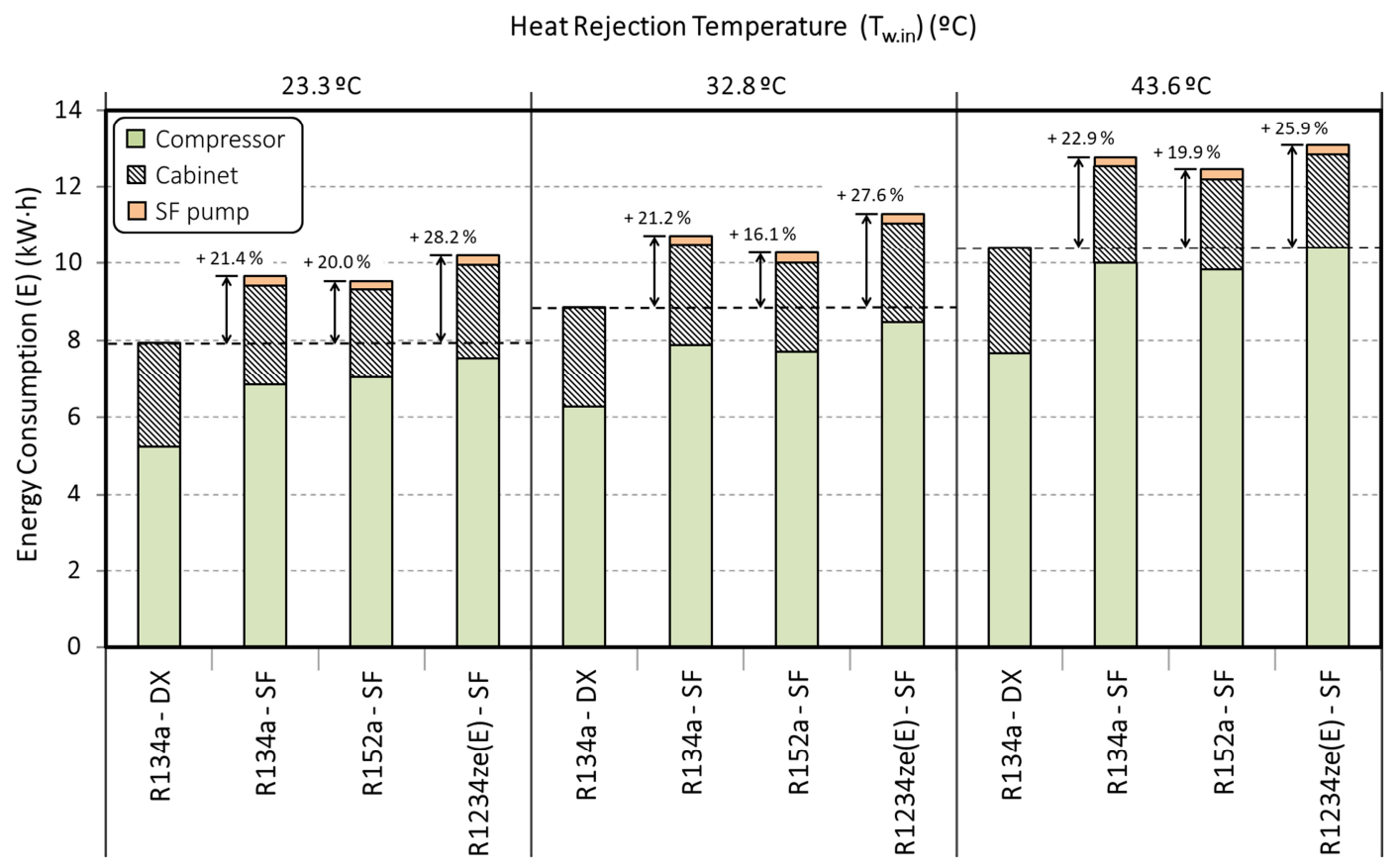

Figure 10 - Energy consumption of each element at different configurations (24 hour-test)

From Table 9 and Figure 10 is evident that the adoption of an indirect configuration entails an increment of energy consumption in the refrigerating plant. The average increment obtained from the experimental tests using Temper $^{\circledR}-20$ as secondary fluid, corresponds to $21.8 \%$ when $\mathrm{R} 134 \mathrm{a}$ is used, $18.7 \%$ if R152a is selected, and finally, $27.2 \%$ if the refrigerant introduced is the HFO R1234ze(E). These values are in accordance with the results presented in the literature review when a direct conversion is performed without introducing more changes in the refrigerating facility. Moreover, the influence of the refrigerant in the main circuit is noticeable and it mainly affects the compressor power consumption and the evaporating cooling capacity as shown in Figures 6 and 2, respectively. The relation of both terms (COP) is presented in the next subsection.

In terms of individual energy consumption, it should be underlined that no appreciable differences have been found for the cabinet and the secondary fluid pump regardless the layout configuration and the refrigerant used in the main circuit. In both cases, the average electrical energy consumption registered was $2.51 \mathrm{~kW} \cdot \mathrm{h}$ with a standard deviation of 0.15 $\mathrm{kW} \cdot \mathrm{h}$, and $0.18 \mathrm{~kW} \cdot \mathrm{h}$ with a standard deviation of $0.08 \mathrm{~kW} \cdot \mathrm{h}$, respectively. Concerning the compressor, the results depicted in Figure 10 evidences that the increment in the energy consumption is mainly due the compressor operation when it is going from a direct to an indirect system. According to Figure 10, the energy impact of the SF-system with regard to DXconfiguration is rated between 31.7 and $44.4 \%$ for R134a; 23.9 and $36.7 \%$ for R152a; and finally, 29.0 and $36.5 \%$ for R1234ze(E).

\subsection{Mass charge reduction}

One of the most important advantages of using indirect expansion system is the reduction of the refrigerant mass charge. This reduction depends on the modifications adopted in the refrigerating plant which basically consist of removing the evaporator and their respective 
liquid and vapour lines used in the direct expansion system. Additionally, an important reduction can be achieved by replacing the liquid receiver by another with less capacity [37]. In this work both actions have been carried out installing a brazed-plate heat exchanger and reducing the liquid receiver from 18 liters to 11 liters. The mass charge used in all cases is reported in Figure 11 where a reduction of $42.5 \%$ in the mass charge of R134a is registered. Regarding R152a and R1234ze(E), the refrigerant mass charge reduction is higher with values of $62.0 \%$ and $52.3 \%$, respectively. These results are lower than those depicted in the literature $[14,15]$ but it needs to be highlighted that the indirect refrigeration system was not optimized for reducing the mass charge.

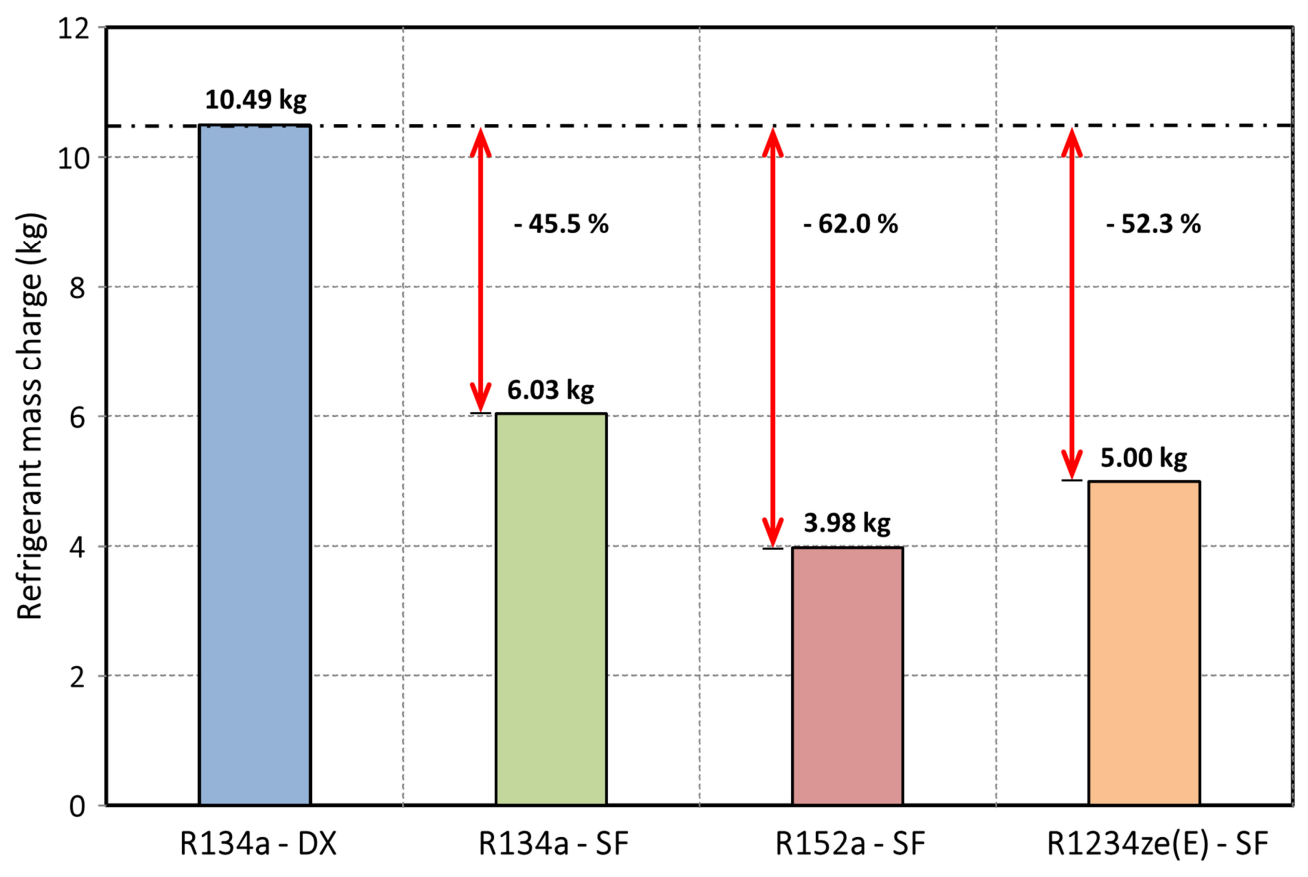

Figure 11 - Refrigerant mass charge and mass reduction for tested configurations

\section{Conclusions}

This work analyses from an experimental point of view the energy impact of converting a direct expansion refrigerating system designed for medium temperature to an indirect one using Temper $^{\circledR}$ as secondary fluid. The experimental plant used in this analysis is devoted to maintain a constant temperature of $2^{\circ} \mathrm{C}$ in a commercial glass door cabinet installed inside a climatic chamber with controlled external conditions of temperature and relative humidity. The analysis was carried out at three different heat rejection temperatures of 43.6, 32.8 and 23.3 으, keeping a constant temperature and relative humidity of $25 \circ \mathrm{C}$ and $55 \%$, respectively, inside the climatic chamber. For direct arrangement R134a was used as refrigerant, while for indirect layout three alternatives have been considered: R134a, R152a and R1234ze(E).

The experimental tests performed during 24 hours have demonstrated that the adoption of an indirect configuration results in an increment of the total energy consumption of the refrigerating plant regardless of the refrigerant adopted. Thus, for R134a the average increment registered for all rejection temperatures was $21.8 \%$, for R152a $18.7 \%$ and for the HFO refrigerant $\mathrm{R} 1234 z e(E), 27.2 \%$. The analysis of these results in more detail revealed 
important differences in the evaporating temperature level which directly affect the cooling capacity of the refrigerating plant. According to the experimental results, the reduction in the evaporating level was ranged from $4.62 \mathrm{~K}$ to $7.20 \mathrm{~K}$, and the reduction in cooling capacity reduction was calculated from $1.57 \%$ (R152a) to $32.51 \%$ (R1234ze(E)). The main consequence of these reductions is the increment of the compressor operating time in an average of $46.4 \%$ with regard to the direct expansion configuration.

Finally, in terms of refrigerant mass charge, the adoption of an indirect system with a replacement of the liquid receiver reduces the refrigerant mass charge up to $42.5 \%$ for R134a, $62.0 \%$ for R152a and $52.3 \%$ for R1234ze(E). These values can be enhanced if an optimized design of the liquid receiver is adopted.

According with the previous results, the use of indirect configuration could be proposed as a possible way to satisfy the constraints imposed by the F-Gas regulations assuming an increment of the total energy consumption. The adoption of this configuration allows extending the lifetime of the refrigerating plant by using drop-in refrigerants with a GWP up to 1500 or middle flammable refrigerants ( $\mathrm{A} 2 \mathrm{~L}$ or $\mathrm{A} 2 \mathrm{~L}$ ) compatible with existing components.

\section{Acknowledgements}

The authors would like to acknowledge the financial support of Universitat Jaume I of Castellón, Spain through the research project P11B2015-66, and the Spanish Ministry of Economy and Competitiveness through the research project ENE2014-53760-R.

\section{References}

[1] SuperSmart. Report 2: Eco-friendly supermarkets - an overview (2016). Available online in: http://www.supersmart-supermarket.info/s/2-eco-friendly-supermarkets-an-overview.pdf

[2] S. A. Tassou, Y. Ge, A. Hadawey, D. Marriott, Energy consumption and conservation in food retailing. Applied Thermal Engineering, 31 (2011), pp. $147-156$.

[3] M. Kauffeld, Trends and perspectives in supermarket refrigeration. IEA Heat Pump Centre Newsletter 28 (4) (2010), pp. $18-23$.

[4] SKM Enviros (Sinclair Knight Merz). Phase Down of HFC Consumption in the EU Assessment of implications for the RAC sector v.11 (2012). Available online in: https://www.epeeglobal.org/wp-content/uploads/EPEE HFC Phase Down Report -

Executive Summary 6964-1.pdf

[5] EPA. Transitioning to low-GWP alternatives in commercial refrigeration. U.S. Environmental Protection Agency (2010). Available online in: https://www.epa.gov/sites/production/files/2015-07/documents/transitioning to lowgwp alternatives in commercial refrigeration.pdf

[6] UNEP. Commercial refrigeration. Fact Sheet 4. UNEP Ozone Secretariat (2015). Available online in: http://conf.montreal-protocol.org/meeting/workshops/hfc management02/presession/English/FS\%204\%20Commercial\%20Refrigeration\%20final.pdf 
[7] EPA. Transitioning to low-GWP alternatives in commercial refrigeration. U.S. Environmental Protection Agency (2016). Available online in: https://www.epa.gov/sites/production/files/2016-

12/documents/international transitioning to lowgwp alternatives in commercial refrigeration.pdf

[8] IPCC/TEAP. Special report: Safeguarding the Ozono layer and the Global climate system. Chapter 4 (2015). Available online in: https://www.ipcc.ch/pdf/specialreports/sroc/sroc full.pdf

[9] UNEP. The Kigali Amendment to the Montreal Protocol: HFC phase-down. OzonAction (2016)

[10] C. H. Stignor, Design of different types of indirect cooling systems in supermarkets Comparison of energy use and costs. SP Work report (2007)

[11] G. S. Kazachki, Secondary coolant systems for supermarkets. ASHRAE Journal September 2006 (2006) pp. $34-46$.

[12] A.. Melinder, Thermophysical properties of aqueous solutions used as secondary working fluids. PhD Thesis. Division of Applied Thermodynamics and Refrigeration. Department of Energy Technology. Royal Institute of Technology, KTH. Stockholm, Sweden (2007). Available online in: http://www.diva-portal.org/smash/get/diva2:12169/FULLTEXT01.pdf

[13] Å. Melinder, Handbook on indirect refrigeration and heat pump systems. IIF-IIR ISBN: 9782362150104 (2015)

[14] V. Minea, Low charge and low emission supermarket refrigeration systems. 8th IIR Gustav Lorentzen Conference on Natural Working Fluids, Copenhagen (2008).

[15] EPA, Revised Draft Analysis of U.S. Commercial Supermarket Refrigeration Systems (2005)

[16] R. Llopis, D. Sánchez, C. Sanz-Kock, R. Cabello, E. Torrella, Energy and environmental comparison of two-stage solutions for commercial refrigeration at low temperature: Fluids and systems, Applied Energy, 138 (2015) pp. 133-142.

[17] V. D. Baxter, IEA Annex 26: Advanced supermarket refrigeration/heat recovery systems. Final report volume 1 (2003). Available in: https://info.ornl.gov/sites/publications/Files/Pub57707.pdf

[18] S. W. Inlow, E. A. Groll, Analysis of secondary-loop refrigeration systems using carbon dioxide as a volatile secondary refrigerant. HVAC\&R Research, 2 (2) (1996) pp. $107-120$.

[19] D. Clodic, C. Le Pellec, I. Darbon, Comparison of Energy Efficiencies of Commercial Refrigeration Direct and Indirect Systems. International Refrigeration and Air Conditioning Conference. Paper 421 (1998). Available in: http://docs.lib.purdue.edu/iracc/421

[20] Y. You, Investigation of deep-freeze refrigeration systems in supermarket application. Master Thesis. Department of Energy Technology. Royal Institute of Technology, KTH. Stockholm, Sweden (2001). 
[21] R. T. Faramarzi, D. H. Walker, Investigation of secondary loop supermarket refrigeration systems. Southern California Edison Foster-Miller, Inc. (2004). Available in: http://www.energy.ca.gov/reports/2004-04-23 500-04-013.PDF

[22] J. Arias, Energy usage in supermarkets - Modelling and field measurements. PhD Thesis. Division of Applied Thermodynamics and Refrigeration. Department of Energy Technology. Royal Institute of Technology, KTH. Stockholm, Sweden (2005). Available in: http://www.divaportal.org/smash/get/diva2:7929/FULLTEXT01.pdf

[23] M. Zhang, Energy analysis of various supermarket refrigeration systems. International Refrigeration and Air Conditioning Conference. Paper 856 (2006). Available in: http://docs.lib.purdue.edu/iracc/856

[24] D. Hinde, S. Zha, L. Lan, $\mathrm{CO}_{2}$ experiences in North American supermarkets. $8^{\text {th }}$ IIR Gustav Lorentzen Conference on Natural Working Fluids. Copenhagen (2008).

[25] T. Nguyen Carbon dioxide in ice rink refrigeration. Master of Sciente Thesis. Division of Applied Thermodynamics and Refrigeration. Department of Energy Technology. Royal Institute of Technology, KTH. Stockholm, Sweden (2012). Available in: http://www.divaportal.org/smash/get/diva2:604747/FULLTEXT01.pdf

[26] D. Sánchez, R. Llopis, R. Cabello, J. Catalán-Gil, L. Nebot-Andrés, Conversion of a direct to

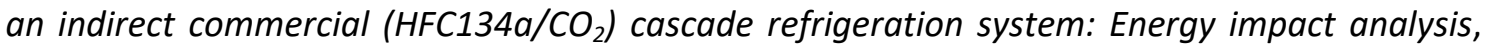
International Journal of Refrigeration, 73 (2017) pp. 183-199.

[27] R. Cabello, D. Sánchez, R. Llopis, I. Arauzo, E. Torrella, Experimental comparison between $R 152 a$ and $R 134 a$ working in a refrigeration facility equipped with a hermetic compressor, International Journal of Refrigeration, 60 (2015) pp. 92-105.

[28] D. Sánchez, R. Cabello, R. Llopis, I. Arauzo, J. Catalán-Gil, E. Torrella, Energy performance evaluation of R1234yf, R1234ze(E), R600a, R290 and R152a as low-GWP R134a alternatives, International Journal of Refrigeration, 74 (2017) pp. 269-282.

[29] ANSI/ASHRAE Standard 34-2013. Designation and Safety Classification of Refrigerants. ISSN: 1041-2336 (2013)

[30] ANSI/ASHRAE Addenda 2015 Supplement. Designation and Safety Classification of Refrigerants. ISSN: 1041-2336 (2015)

[31] E. W. Lemmon, M. L. Huber, M. O. McLinden, Reference fluid thermodynamic and transport properties (REFPROP), NIST Standard Reference Database 23, v.9.1. National Institute of Standards 2013. Gaithersburg MD, USA.

[32] R. Cabello, R. Llopis, D. Sánchez, REFLAB: An interactive tool for supporting practical learning in the educational field of refrigeration. International Journal of Engineering Education. 27(4) pp. 909 - 918 (2011)

[33] ASHRAE Handbook - Fundamentals (SI Edition), 2005 Edition, American Society of Heating, Refrigerating and Air Conditioning Engineers, Englewood, Colorado (USA) (2005). 
[34] S. Uemura, S. Inagaki, N. Kobayashi, T. Teraoka, M. Noguchi, Characteristics of HFC refrigerants. International Refrigeration and Air Conditioning Conference at Purdue, Paper 177 (1992). Available at: http://docs.lib.purdue.edu/iracc/177

[35] S. F. Yana Motta, E. D. Vera Bercerra, M. W. Spatz, Analysis of LGWP alternatives for small refrigeration (Plugin) applications. International Refrigeration and Air Conditioning Conference at Purdue, Paper 1149 (2010). Available at: http://docs.lib.purdue.edu/iracc/1149

[36] J. Zhang, A. Desideri, M. R. Kaem, T. S. Ommen, J. Wronski, F. Haglind, Flow boiling heat transfer and pressure drop characteristics of R134a, R1234yf and R1234ze in a plate heat exchanger for organic Rankine cycle units, International Journal of Heat and Mass Transfer. 108 (B) pp. 1787 - 1801 (2017).

[37] Corberán J., Refrigerant charge reduction in refrigerating systems. $25^{\text {th }}$ Informatory note on refrigeration technologies. International Institute of Refrigeration (2014). Available at: http://www.iifiir.org/userfiles/file/publications/notes/NoteTech 25 EN.pdf 